\title{
Measurements and modelling of snow particle size and shortwave infrared albedo over a melting Antarctic ice sheet
}

\author{
R. Pirazzini, P. Räisänen, T. Vihma, M. Johansson, and E.-M. Tastula \\ Finnish Meteorological Institute, Helsinki, Finland \\ Correspondence to: R. Pirazzini (roberta.pirazzini@fmi.fi) \\ Received: 12 March 2015 - Published in The Cryosphere Discuss.: 30 June 2015 \\ Revised: 20 October 2015 - Accepted: 11 November 2015 - Published: 15 December 2015
}

\begin{abstract}
The albedo of a snowpack depends on the singlescattering properties of individual snow crystals, which have a variety of shapes and sizes, and are often bounded in clusters. From the point of view of optical modelling, it is essential to identify the geometric dimensions of the population of snow particles that synthesize the scattering properties of the snowpack surface. This involves challenges related to the complexity of modelling the radiative transfer in such an irregular medium, and to the difficulty of measuring microphysical snow properties. In this paper, we illustrate a method to measure the size distribution of a snow particle parameter, which roughly corresponds to the smallest snow particle dimension, from two-dimensional macro photos of snow particles taken in Antarctica at the surface layer of a melting ice sheet. We demonstrate that this snow particle metric corresponds well to the optically equivalent effective radius utilized in radiative transfer modelling, in particular when snow particles are modelled with the droxtal shape. The surface albedo modelled on the basis of the measured snow particle metric showed an excellent match with the observed albedo when there was fresh or drifted snow at the surface. In the other cases, a good match was present only for wavelengths longer than $1.4 \mu \mathrm{m}$. For shorter wavelengths, our modelled albedo generally overestimated the observations, in particular when surface hoar and faceted polycrystals were present at the surface and surface roughness was increased by millimetre-scale cavities generated during melting. Our results indicate that more than just one particle metric distribution is needed to characterize the snow scattering properties at all optical wavelengths, and suggest an impact of millimetre-scale surface roughness on the shortwave infrared albedo.
\end{abstract}

\section{Introduction}

The snowpack is composed of snow crystals (grains) more or less bounded with each other, which have shapes and sizes that change during the metamorphism process. The boundaries between grains are not always identifiable, and X-ray micro-tomography has revealed a much more complex structure than usually described by a single grain size value and a morphological description (Schneebeli and Sokratov, 2004). Nevertheless, the snow grain size is a fundamental quantity used in radiative transfer modelling to characterize the scattering properties of the snowpack and to determine its degree of metamorphism (Flanner and Zender, 2006). As such, it is an essential parameter for the interpretation of the reflected signals in optical and radar remote sensing, and it is used in the most sophisticated simulations of snow surface albedo, snow mass and energy budget and length of melting season, as well as in water runoff estimation and avalanche risk assessment.

The scattering properties of snow grains are wavelength dependent, and the impact of snow layering on the surface reflectance varies according to the penetration depth of the considered wavelength. Snow grain size variations have a larger impact on the near-infrared (NIR, 0.7-1.0 $\mu \mathrm{m}$ ) and shortwave infrared (SWIR, 1.0-2.5 $\mu \mathrm{m}$ ) reflectance compared to the visible (VIS, 0.35-0.7 $\mu \mathrm{m}$ ) reflectance (Wiscombe and Warren, 1980) because grains absorb more radiation in the NIR and SWIR spectral regions. Thus, a selected NIR or SWIR wavelength, or a combination of wavelengths, is utilized to retrieve snow grain size from in situ or remote sensing reflectance observations (Gallét et al., 2009; Kokhanovsky et al., 2011; Nolin and Dozier, 2000; Painter et al., 2007). 
The relationship between the snow surface reflectance and the shape and size distribution of the snow grains is not trivial and not yet fully understood. Snow crystals of different shapes and sizes coexist at the surface and in the sub-surface layers reached by the solar radiation. Generally, variability in snow crystal size and shape is largest at the surface, which is the layer that mostly contributes to the surface reflectance. In most radiative transfer models, snow is represented with an optically equivalent "effective radius" $\left(r_{\text {oeff }}\right)$, which is the radius of a collection of mono-disperse spheres having a total volume-to-surface area-ratio equal to that of the true snow grain population (Grenfell and Warren, 1999). The hypothesis behind this formulation is that the collection of spheres possesses the same scattering properties as the physical snow grain population. Indeed, in the case of spheres and randomly oriented convex particles, the volume-to-surface-area equivalent radius $\left(r_{\mathrm{VA}}\right)$ coincides with the mean radius of the particle ensemble weighted by the particle's projected area $\left(r_{\mathrm{VP}}\right.$, Cauchy, 1841), which is directly proportional to the particle's scattering contribution (Hansen and Travis, 1974).

The equivalent sphere approximation has been extensively applied in the optical retrieval of the snow grain effective radius by using radiative transfer inversion algorithms which utilize the measured radiance (Kokhanovsky et al., 2011; Lyapustin et al., 2009; Nolin and Dozier, 2000; Painter et al., 2007; Scambos et al., 2007; Stamnes et al., 2007). As $r_{\mathrm{VA}}$ is directly related to the snow specific surface area (SSA) through the relationship

$\mathrm{SSA}=3 / \rho_{\text {ice }} r \mathrm{VA}$,

where $\rho_{\text {ice }}$ is the ice density, measurements of SSA have been used to model the radiative properties of snow (Carmagnola et al., 2013; Dominé et al., 2006; Gallet et al., 2011). The usage of SSA has its advantages: (1) the difficult identification of the single snow crystals is not required; (2) SSA is an unambiguous and well defined quantity; (3) accurate measurement methods are available (based on stereology, X-ray tomography, and gas-absorption); and (4) fast, indirect optical measurement methods have recently been developed (Arnaud et al., 2011; Berisford et al., 2013; Gallet et al., 2009). However, SSA (and $r_{\mathrm{VA}}$ ) describes the scattering property of the snow only in the case of convex grains. In the case of concave grains, the volume-to-total surface area equivalent radius is less than the volume-to-projected area equivalent radius: $r_{\mathrm{VA}}<r_{\mathrm{VP}}$.

Model calculations have shown that grains with the same optically equivalent radius but different shapes result in different snow albedo (Jin et al., 2008; Mishchenko et al., 1999; Picard et al., 2009). The impact of shape on the reflectance of a flat snow surface is particularly profound for large solar zenith angle and wavelength due to the decreasing role of multiple scattering and, thus, the increasing importance of the single scattering properties of the grains, in particular the shape-specific phase function.
A large number of methods have been applied to measure the snow grain geometry. This is due to the complex and laborious nature of these measurements, but also due to the uncertainty on what is the most relevant dimension for the different applications (optical and microwave radiative transfer, glaciological studies, avalanche forecasting). A snow grain is by definition a single crystal (Fierz et al., 2009), but in many snow grain analyses there is no distinction between single crystals and multi-crystals objects or aggregates (Aoki et al., 2000; Gay et al., 2002). The "size" of a grain is defined as its greatest extension according to the International Classification (Colbeck et al., 1990; Fierz et al., 2009), and the grain size of a snow sample is the average size of its characteristic grains. However, this grain metric is not suitable for optical applications: Mätzler (1997) and Neshyba et al. (2003) demonstrated that the shortest grain dimension is proportional to $r_{\mathrm{VA}}$, and there is also experimental evidence that this dimension best represent the scattering properties of the snow grains (Grenfell et al., 1981; Aoki et al., 2000, 2003, 2011).

An implication of all these considerations is that extensive and detailed snow and albedo observations are needed to establish the link between the snowpack microphysical characteristics and surface albedo, and to verify the radiative transfer model assumptions in snow-radiation interaction. Data sets including contemporary in situ observations of albedo and grain texture are few, compared to the large variety of existing snow conditions (Aoki et al., 2000; Carmagnola et al., 2013; Dominé et al., 2006; Nakamura et al., 2001; Painter and Dozier, 2004). These data sets only include short measurement periods, as both spectral albedo and snow observations rely on very laborious and time consuming methods.

In this study we analyzed snow and albedo data collected in Dronning Maud Land, Antarctica, in the austral summer 2009-2010. As we wanted to examine real snow particle dimensions, shapes, and size distributions, we took twodimensional (2-D) macro photos of snow grains. More sophisticated and accurate methods to measure snow morphology (as 3-D microscope stereology, X-ray tomography, and gas absorption techniques) do exist, but we wanted to explore the capability of a technically simpler method to obtain optically relevant snow particle dimensions. The sampling procedure is particularly critical in all techniques employed to measure the snow texture. Both direct and indirect methods disturb the target sample in one way or another. In our case, the snow samples consisted of disaggregated snow particles, some of which were single crystals and some multi-crystals and aggregated grains. Hereafter, we adopt the term "particle" to indicate an observed single snow element, which may or may not consist of a single crystal, and which is considered to be a distinct optical scatterer/absorber. In this study, we hypothesize that the shortest skeleton branch of the 2-D projection of the snow particle is a close approximation of the shortest particle dimension, and we develop an objective method to obtain this metric from the 2-D macro photos. The 
Table 1. Snow pit and spectral reflectance measurement times during clear and overcast days, mean solar zenith angle $\left(\theta_{0}\right)$ during the clear-sky reflectance measurements, as well as the mean value and standard deviation of the air temperature $\left(T_{\mathrm{a}}\right)$, relative humidity $(\mathrm{RH})$, wind speed $(V)$, and wind direction (Dir) during the time frame covered by the snow and reflectance measurements. The last column gives the mean, minimum, and maximum air temperature in the $24 \mathrm{~h}$ preceding the corresponding snow pit measurements $\left(\overline{\mathrm{T} 24_{\mathrm{a}}}\right.$, T24 $4_{\mathrm{a}, \mathrm{min}}$, and $\mathrm{T} 24_{\mathrm{a}, \mathrm{max}}$, respectively). Local solar time is approximately UTC $-54 \mathrm{~min}$.

\begin{tabular}{llrlrrrrrl}
\hline Date & Sky & $\begin{array}{r}\text { Time of } \\
\text { snow pit } \\
\text { (UTC) }\end{array}$ & $\begin{array}{l}\text { Time of } \\
\text { reflectance } \\
\text { (UTC) }\end{array}$ & $\theta_{0}$ & $T_{\mathrm{a}}\left({ }^{\circ} \mathrm{C}\right)$ & $\mathrm{RH}(\%)$ & $V\left(\mathrm{~m} \mathrm{~s}^{-1}\right)$ & Dir $\left({ }^{\circ}\right)$ & $\begin{array}{l}\overline{\mathrm{T} 24_{\mathrm{a}}}\left[\mathrm{T} 24_{\mathrm{a}, \mathrm{min},}\right. \\
\left.\mathrm{T} 24_{\mathrm{a}, \mathrm{max}}\right]\end{array}$ \\
\hline 23 Dec & Overc & $10: 19$ & $11: 50$ & & $-6.0 \pm 0.3$ & $83 \pm 5$ & $5.7 \pm 0.5$ & $81 \pm 5$ & $-6.1[-7.7,-4.8]$ \\
26 Dec & Clear & $11: 35$ & $12: 25$ & 49.9 & $-5.3 \pm 0.3$ & $64 \pm 7$ & $2.1 \pm 0.7$ & $133 \pm 38$ & $-7.2[-13.4,-4.2]$ \\
29 Dec & Clear & $10: 55$ & $14: 19$ & 51.1 & $-4.4 \pm 0.4$ & $58 \pm 5$ & $2.6 \pm 1.0$ & $140 \pm 18$ & $-6.0[-9.1,-3.0]$ \\
5 Jan & Clear & $09: 50$ & $10: 19$ & 55.1 & $0.5 \pm 0.6$ & $57 \pm 4$ & $4.9 \pm 1,3$ & $65 \pm 6$ & $-0.4[-5.7,3.1]$ \\
6 Jan & Clear & $10: 00$ & $10: 34$ & 54.5 & $-1.3 \pm 0.3$ & $58 \pm 2$ & $4.2 \pm 0.7$ & $80 \pm 12$ & $-1.8[-7.6,1.1]$ \\
12 Jan & Clear & $11: 17$ & $09: 57,11: 54$ & 54.9 & $-4.2 \pm 0.5$ & $72 \pm 5$ & $2.3 \pm 0.8$ & $116 \pm 52$ & $-3.2[-7.5,-0.4]$ \\
14 Jan & Overc & $11: 10$ & $09: 44$ & & $-2.5 \pm 0.1$ & $76 \pm 1$ & $5.6 \pm 0.4$ & $74 \pm 7$ & $-4.2[-6.3,-2.5]$ \\
19 Jan & Clear & $10: 50$ & $09: 44,11: 50$ & 56.8 & $-3.9 \pm 0.3$ & $77 \pm 1$ & $7.9 \pm 1.3$ & $166 \pm 2$ & $-2.1[-6.1,0.8]$ \\
\hline
\end{tabular}

advantage and interest of using 2-D macro photos to measure optical particle size compared to the faster, indirect optical methods lie in the direct and independent quantification of the snow particle metric distribution. 2-D particle projections allow the investigation of the impact of particle morphology and size distribution on the measured albedo, and offer the possibility to extract more than one metric per particle distribution. Indeed, we will demonstrate in this study that, in some cases, $r_{\text {oeff }}$ and, consequently, the appropriate particle metric, depend on wavelength. The main objectives of the present paper are (1) to verify if the proposed particle metric (the shortest skeleton branch) adequately synthesizes the scattering properties of the snowpack, and (2) to verify if the measured vertical profiles of snow density and particle metric distribution give suitable and sufficient information to model the surface albedo. The schematic diagram of Fig. 1 illustrates the flow of the work: particle metric distributions were calculated from the snow images, and, along with the measured snow density, were fed into the radiative transfer model DISORT (Discrete Ordinates Radiative Transfer Program for a Multi-Layered Plane-Parallel Medium, Stamnes et al., 1988) to calculate the corresponding surface albedo. The modelled spectral albedo was then compared to the observations, and the particle effective radii derived from the particle metric distributions were compared with the optical effective radii calculated from the observed surface albedo. The structure of the paper is as follows: after describing the snow and radiation data sets in Sect. 2, the methods utilized to analyse the data and to model the surface albedo are presented in Sect. 3. Results are illustrated in Sect. 4 and further discussed in Sect. 5. In Sect. 6 the main results are summarized, and the conclusions drawn. To increase the readability of the text, all the acronyms and symbols utilized in the various Sections are listed in Table A1.

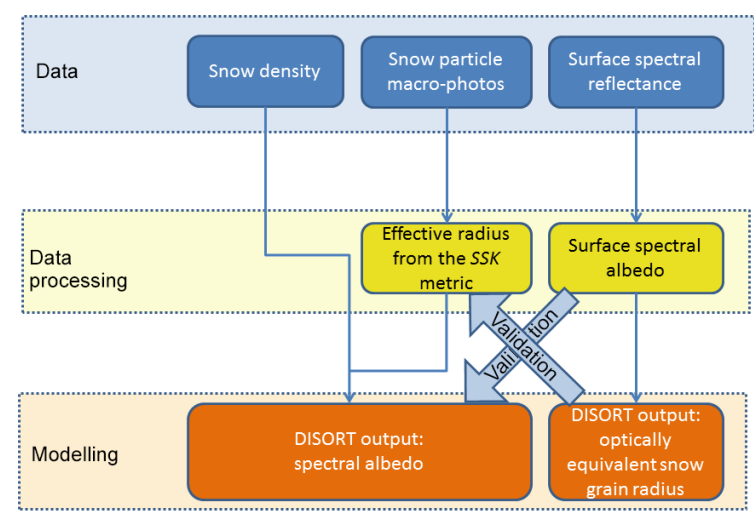

Figure 1. Work flow diagram.

\section{Observations}

The snow particle size and radiation data analyzed here were collected during the austral summer 2009-2010 over an ice sheet near the Finnish Antarctic station Aboa $\left(73^{\circ} 03^{\prime} \mathrm{S}\right.$, $13^{\circ} 25^{\prime} \mathrm{W}, \sim 200 \mathrm{~m}$ a.s.l.). The ice sheet was gently sloping (with a local inclination of about $0.5^{\circ}$ ) towards an ice shelf, the edge of which was approximately $130 \mathrm{~km}$ to the northwest. The data set includes measurements taken during 2 overcast and 6 clear-sky days (Table 1): in the morning or around noon, vertical profiles of snow density, temperature, and particle macro photos were acquired from a snow pit. Surface spectral reflectance was measured in a close-by undisturbed area, with a time difference from the snow pit measurements ranging from 0.5 to $3.5 \mathrm{~h}$ (Table 1 ). 
Table 2. Uncertainties on the vertical profiles of snow temperature $\left(T_{\text {snow }}\right)$ and density $\left(r_{\text {snow }}\right)$, calculated as the square root of the sum of the squares of instrumental error and intra-pit variability. The intra-pit variability is given in parentheses.

\begin{tabular}{llcllcl}
\hline & Surface & $2.5 \mathrm{~cm}$ & $5 \mathrm{~cm}$ & $10 \mathrm{~cm}$ & $15 \mathrm{~cm}$ & $20 \mathrm{~cm}$ \\
\hline$T_{\text {snow }}\left({ }^{\circ} \mathrm{C}\right)$ & $\pm 0.3( \pm 0.1)$ & $\pm 0.3( \pm 0.1)$ & $\pm 0.3( \pm 0.1)$ & $\pm 0.30( \pm 0.05)$ & $\pm 0.3( \pm 0.1)$ & $\pm 0.3( \pm 0.1)$ \\
$r_{\text {snow }}\left(\mathrm{kg} \mathrm{m}^{-3}\right)$ & $\pm 45( \pm 16)$ & & $\pm 13( \pm 10)$ & $\pm 15( \pm 12)$ & & $\pm 14( \pm 12)$ \\
\hline
\end{tabular}

\subsection{Meteorological conditions}

The shape and size of the near-surface snow particles are strongly affected by the current and previous meteorological conditions. To interpret the snow particle observations, we calculated the mean and standard deviation of the air temperature $T_{\mathrm{a}}$ (at the height of $3.5 \mathrm{~m}$ ), air relative humidity $(2.4 \mathrm{~m})$, as well as wind speed and direction $(10 \mathrm{~m})$ for the time frame covered by the snow pit and reflectance measurements (Table 1). In addition, we report in Table 1 the mean, minimum, and maximum $T_{\mathrm{a}}$ in the $24 \mathrm{~h}$ period preceding the snow particle observations. The humidity and wind values are based on measurements at an Aanderaa weather mast. The weather mast data on air temperature included, however, errors due to sensor heating by reflected solar radiation (the radiation shields were not protective enough for radiation reflected from the surface). Hence, we calculated the air temperature from sonic anemometer measurements, which are not affected by radiation. The temperature that a sonic anemometer yields is within about $0.20 \%\left(0.5^{\circ} \mathrm{C}\right)$ of the virtual temperature, which we converted to the true air temperature following Sjöblom and Smedman (2002). Both the weather mast and sonic anemometer were located within $200 \mathrm{~m}$ of the snow measurement site. The air temperature remained below $0{ }^{\circ} \mathrm{C}$ during all days except 5 January, when the wind was from the Basen Nunatak, where the rocky surface was strongly heated by clear-sky solar radiation. During all examined cases wind was generally light or gentle. Assuming that, in the case of dry snow at the surface, the threshold wind speed at the height of $0.5 \mathrm{~m}$ for the occurrence of snowdrift was $6 \mathrm{~ms}^{-1}$, the longest snowdrift episode (about $18 \mathrm{~h}$ ) occurred between the midday of 23 December and the morning of 24 December, while shorter episodes (a few hours) occurred on 28 and 29 December. Later during the campaign, the surface melting taking place before or during the high wind episodes prevented the snowdrift. Light snowfall occurred on 22 and 23 December, and on 1, 8, 13, 17, and 18 January, but the amount of precipitation was not recorded. The $24 \mathrm{~h}$ preceding the snow observations in the two overcast cases (23 December and 14 January) were characterized by overcast conditions and small $T_{\mathrm{a}}$ excursions $\left(2.9\right.$ and $3.8^{\circ} \mathrm{C}$, respectively). The largest $T_{\mathrm{a}}$ excursion $\left(9.2^{\circ} \mathrm{C}\right)$ was recorded in the $24 \mathrm{~h}$ preceding the clear-sky case of 26 December, mostly due to the strong nocturnal cooling $\left(T_{\mathrm{a}}\right.$ minimum was $\left.-13.4^{\circ} \mathrm{C}\right)$. Later in the season, the nocturnal cooling was less pronounced $\left(T_{\mathrm{a}}\right.$ minimum was between -9.1 and $\left.-5.7^{\circ} \mathrm{C}\right)$.

\subsection{Snow density and temperature}

Similarly to our campaigns in 2006-2007 and 2007-2008 (Vihma et al., 2011), snow temperature and density profiles were measured in the uppermost $50 \mathrm{~cm}$ of the snow pits, but here we only present and utilize data from the uppermost $20 \mathrm{~cm}$. Snow temperature $\left(T_{\text {snow }}\right)$ was measured at the surface and at the depths of $2.5,5,10,15$, and $20 \mathrm{~cm}$ with the handheld temperature probe Ebro TFX 410, which is equipped with a $30 \mathrm{~cm}$ probe and has a nominal accuracy of $\pm 0.3{ }^{\circ} \mathrm{C}$. The vertical snow density ( $\rho_{\text {snow }}$ ) profiles were measured with a steel cylinder (volume $247 \mathrm{~cm}^{3}$ ) pushed horizontally in the snow pit wall. The cylinder has a diameter of $5 \mathrm{~cm}$, and snow samples were taken with the centre of the cylinder at the depths of 5,10 , and $20 \mathrm{~cm}$. $r_{\text {snow }}$ in the uppermost $2 \mathrm{~cm}$ was measured using a small aluminium box $\left(48 \mathrm{~cm}^{3}, \sim 5 \times 5 x \times 2 \mathrm{~cm}\right)$. The samples were weighted using a digital balance with an accuracy of $0.002 \mathrm{~kg}$. For each snow pit, two vertical profiles of temperature and density were measured, within approximately $40 \mathrm{~cm}$ of each other, in a time interval of about $15 \mathrm{~min}$. In our analyses and model simulations of the surface albedo, we utilized the mean of the two vertical profiles of $r_{\text {snow }}$ and $T_{\text {snow }}$ for each snow pit, and we estimated their uncertainty as the square root of the sum of the squares of instrumental error and intra-pit variability (Table 2). We define the intra-pit variability as twice the intrapit standard deviation of density and temperature based on all the snow pits measured during the campaign ( 45 and 47 snow pits for temperature and density, respectively).

In addition to the intra-pit variability, snow density and temperature varied also at larger horizontal scales, as detected via measurements at $10 \mathrm{~m}$-intervals along a $100 \mathrm{~m}$ long line, on 6 days for density and 8 days for temperature. The standard deviation of density in the uppermost $2 \mathrm{~cm}$ was largest $\left(87 \mathrm{~kg} \mathrm{~m}^{-3}\right)$ on 26 December, after the snow redistribution associated to the snowdrift event of 23-24 December, and smallest $\left(38 \mathrm{~kg} \mathrm{~m}^{-3}\right)$ in the afternoon of 19 January after a period of strong melt. The standard deviation was large $\left(72 \mathrm{~kg} \mathrm{~m}^{-3}\right)$ also on 14 January after a precipitation event. Horizontal variations in snow surface temperature were largest in cold conditions (standard deviation $0.4^{\circ} \mathrm{C}$ ) and naturally very small during melt. For snow density, the standard deviation strongly decreased with depth, whereas for snow temperature it remained rather constant in the uppermost $20 \mathrm{~cm}$, which was the case also at the intra-pit scale (Table 2). 
Figure 2 shows the mean snow pit $T_{\text {snow }}$ and $r_{\text {snow }}$ profiles for the eight analyzed cases. The warming of the snowpack during the progress of the summer is clearly evident, with a marked melting and an almost vertically constant profile at $0{ }^{\circ} \mathrm{C}$ in the last 3 analyzed days (Fig. 2a). The $r_{\text {snow }}$ profiles show a progressive compaction of the snowpack for most of the layers, but not for the surface. Particularly on 14 and 19 January, during the strong melting, $\rho_{\text {snow }}$ was much lower at the surface than in the underlying layers (Fig. 2b). The highest $r_{\text {snow }}$ exceeding $500 \mathrm{~kg} \mathrm{~m}^{-3}$ were due to the presence of ice layers formed via refreezing of meltwater; such high $\rho_{\text {snow }}$ values were not observed during our previous campaigns at the same site in 2006-2008, when the summers were colder (Vihma et al., 2011).

\subsection{Near-surface snow stratigraphy}

Stratigraphy observations were only made at a qualitative level, without snow hardness measurements and systematic recording of layer properties. However, the collected information provided a useful picture of the evolution of the uppermost snowpack layers. For most of the measurement period, the snow surface was very hard. On 23 December the surface was covered with a mixture of small rounded particles (code RGsr, greatest extent of $0.2-0.5 \mathrm{~mm}$ ), faceting rounded particles (code RGxf, greatest extent of 0.5-1 mm), and aggregates ("Agg", greatest extent of 1-1.5 mm). Moreover, a thin $(0.1-0.2 \mathrm{~cm})$ ice layer was present at $10 \mathrm{~cm}$ depth. At $5 \mathrm{~cm}$ depth, rounding faceted particles of various sizes (code FCxr, greatest extent of $0.2-2 \mathrm{~mm}$ ) were present. On the morning of 26 December, a wind-packed surface crust covered with very fine rounding faceted particles (greatest extent of $0.1-0.6 \mathrm{~mm}$ ) was observed, both at the surface and at $5 \mathrm{~cm}$ depth. Ice layers were present at the depths of 8 and $10 \mathrm{~cm}$. From 28 December to 3 January, the uppermost $2 \mathrm{~cm}$ layer was refrozen both in the morning and evening observations. Although surface snow temperature started reaching $0^{\circ} \mathrm{C}$ only on 1 January, subsurface melting due to absorption of solar radiation likely occurred also in the previous days, as for instance in the $24 \mathrm{~h}$ before the clear-sky case of 29 December, when maximum $T_{\mathrm{a}}$ was $-3.0^{\circ} \mathrm{C}$. On $29 \mathrm{De}-$ cember, rounded particles (code RGlr, greatest extension of $0.2-0.8 \mathrm{~mm}$ ) and rounded irregular polycrystals (code MFpc, greatest extension of $1-3 \mathrm{~mm}$ ) extended from the surface to the depth of $5 \mathrm{~cm}$ (the surface appearance on 29 December is shown in Fig. 3a). With the progress of the melting, the refrozen layer at the top extended to the depth of $15 \mathrm{~cm}$ in the evening of 5 January, and to the depth of $20 \mathrm{~cm}$ in the evening of 13 January. On 5 January, a mixture of thin faceted particles (code FCsf, greatest extent of $0.1-0.5 \mathrm{~mm}$ ), rounding faceted polycrystals and rounding surface hoar (code SHxr) measuring 1-2 $\mathrm{mm}$ at greatest extent, and thin protrusions of 0.05-0.3 mm diameter was present at the surface (Fig. 3b). By 7 January they extended to the uppermost $5 \mathrm{~cm}$, forming a highly porous but still hard layer (at least when air tem-
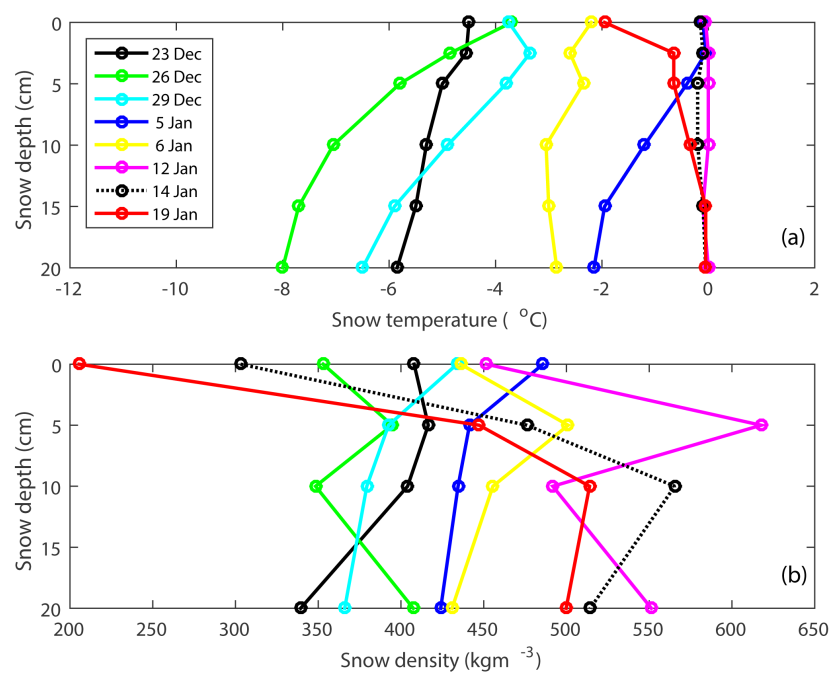

Figure 2. Vertical profiles of snow temperature and density in the uppermost $20 \mathrm{~cm}$ of the snowpack for the analyzed clear and overcast cases. Each profile results from the average of two almost simultaneous profiles, taken $0.4 \mathrm{~m}$ apart. The surface density measurements were taken with a $2 \mathrm{~cm}$-tall sampler, and therefore represent an average of the uppermost $2 \mathrm{~cm}$ of the snowpack. At the deeper layers, the snow density samples were taken using cylinders with axes centred at $5,10,15$, and $20 \mathrm{~cm}$ depths.

perature was below $0{ }^{\circ} \mathrm{C}$ ). In the following days, the surface roughness at the centimetre and millimetre scale increased, more as a result of the undergoing snow metamorphism than due to the action of the wind (which was generally light). In the morning of 12 January, after a clear-sky night, striated, sharp-edged surface hoar (code SHsu, greatest extent of $1-1.3 \mathrm{~mm}$ ) was present at the surface, together with rounded polycrystals measuring $1-2 \mathrm{~mm}$ at their greatest extent and small protrusions of $0.05-0.2 \mathrm{~mm}$ diameter. At the $5 \mathrm{~cm}$ depth, the particle population was a mixture of rounded polycrystals (greatest extent of $1-2.5 \mathrm{~mm}$ ) and rounded particles (greatest extent of $0.2-0.7 \mathrm{~mm}$ ). After the snowfall on 13 January, the surface was smoothed and the concavities were filled by fine, irregular snow crystals (code PPir). Starting on 14 January, the coarse grains forming the $0-5 \mathrm{~cm}$ layer became gradually looser, and the snow layer softened. On 14 January faceted polycrystals (greatest extension of $1-2 \mathrm{~mm}$ ) together with partly decomposed precipitation particles (code DFdc, greatest extent of $0.1-0.5 \mathrm{~mm}$ ) were observed at the surface. On 18 January, a light snowfall refreshed and smoothed again the snow surface (Fig. 3c), and on 19 January columns and needles (greatest extent of 0.2 $0.7 \mathrm{~mm}$ ) together with rounding faceted polycrystals (greatest extent of 1-2 mm) were present at the surface. A summary of the size and shape characteristics of the surface snow particles is given in Table 3 . 
Table 3. Classification of size and shape of the observed surface snow particles according to Fierz et al. (2009). See Sect. 2.3 for explanation of the shape codes.

\begin{tabular}{ll}
\hline Date & Greatest dimension $(\mathrm{mm}) /$ shape class \\
\hline 23 Dec & $0.2-0.5 / \mathrm{RGsr}, 0.5-1 / \mathrm{RGxf}, 1-1.5 / \mathrm{Agg}^{*}$ \\
26 Dec & $0.1-0.6 / \mathrm{FCxr}$ \\
29 Dec & $0.2-0.8 / \mathrm{RGlr}, 1-3 / \mathrm{MFpc}$ \\
5 Jan & $0.1-0.5 / \mathrm{FCsf}, 1-2 / \mathrm{MFpc}, 1-2 / \mathrm{SHxr}$ \\
6 Jan & $0.1-0.5 / \mathrm{FCsf}, 1-2 / \mathrm{MFpc}, 1-2 / \mathrm{SHxr}$ \\
12 Jan & $1-1.3 / \mathrm{SHsu}, 1-2 / \mathrm{MFpc}$ \\
14 Jan & $0.1-0.5 / \mathrm{DFdc}, 1-2 / \mathrm{MFpc}$ \\
19 Jan & $0.2-0.7 / \mathrm{PPco}, 0.2-0.7 / \mathrm{PPnd}, 1-2 / \mathrm{MFpc}$ \\
\hline * Agg (aggregate) does not belong to the shape classification of \\
Fierz et al. (2009), but it is adopted in both observational studies \\
(Fujiyoshi and Wakahama, 1985) and snow models (Jin et al., 2008; \\
Liou et al., 2011; Yang et al., 2013).
\end{tabular}

\subsection{Snow particle samples}

To ensure the possibility of photographing snow particle samples in all temperature, wind, and illumination regimes, we dug a $2 \mathrm{~m}$ deep cave in the snowpack. The bottom of the cave was at a constant temperature of about $-7^{\circ} \mathrm{C}$. A wooden plate covered the cave, sheltering it from wind and solar radiation (Fig. 4a). To photograph the snow particles, during each snow pit excavation a block of snow including the surface layer down to the depth of $30-40 \mathrm{~cm}$ was extracted and transported in the nearby snow cave. To extract the snow particles from the block, we brushed the snow surface with a thin and flexible steel palette knife, detaching the snow particles from the background snowpack texture. Particles were collected on a slide glass, which was then placed in a holder attached to the camera support system (Fig. 4b). We tried to avoid contact and overlapping between particles, often resampling the particles several times, in order to facilitate the segmentation during the image processing (see Sect. 3.1.1). We did not screen out either crystal fragments or natural clusters of grains, as we wanted to include also these particles in our analysis. The particles were illuminated from below, with a bulb covered by a thick layer of white polyethylene foam to diffuse the light and prevent the heating of the glass. Macro photos were taken with a Canon EOS 450D digital camera equipped with a $60 \mathrm{~mm}$ macro lens and a $68 \mathrm{~mm}$ extension tube.

\subsection{Snow nadir reflectance}

Snow spectral reflectance (in the range $0.35-2.5 \mu \mathrm{m}$ ) was measured with an ASD FieldSpec JR spectroradiometer manufactured by Analytical Spectral Devices, Inc. (hereinafter referred to as ASD), now PANalytical. The ASD has three sensors covering three distinct spectral regions: visible and near-infrared (VNIR, 0.35-1.0 $\mu \mathrm{m})$, shortwave infrared 1 (SWIR1, 1.0-1.83 $\mu \mathrm{m}$ ), and shortwave infrared 2

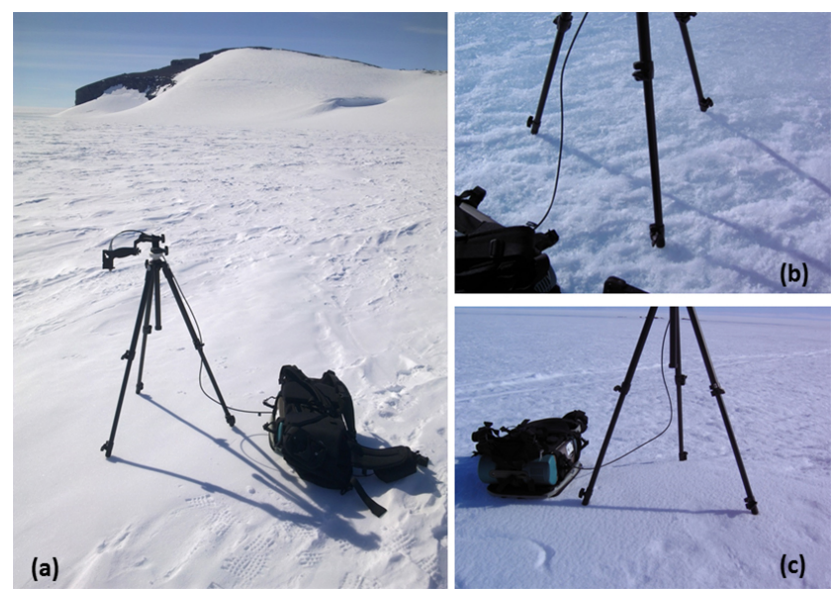

Figure 3. ASD spectroradiometer measuring snow reflectance as the surface texture changed over the measuring period: a very smooth surface on 29 December 2009 (a), a rough surface on 5 January 2010 (b), and a moderately rough surface on 19 January 2010, after a light snowfall (c).
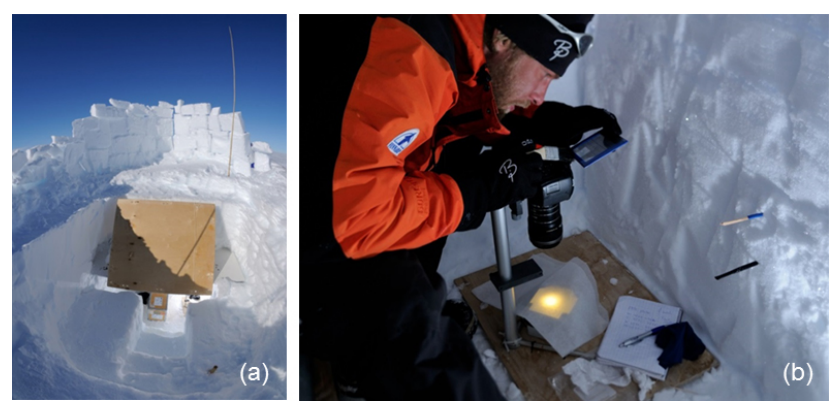

Figure 4. The cave dug in the snowpack (a) created a cold environment, sheltered from wind and radiation, which was suitable for snow macrophotography (b). Photos by Timo Palo.

(SWIR2, 1.83-2.5 $\mu \mathrm{m}$ ), with a spectral resolution between 3 and $10 \mathrm{~nm}$. Snow relative reflectance was obtained from the ratio of the snow radiance to the reference radiance, reflected from an almost-Lambertian Spectralon target. The relative reflectance was then multiplied with the calibration data of the reference panel to get the absolute snow spectral reflectance. Snow and reference radiances were acquired using the ASD bare fore optic (with a nominal field of view of $25^{\circ}$ ) pointing toward nadir, and both of them were consecutively measured 30 times. The acquisition time of the 60 spectra was about $6 \mathrm{~min}$. The spectrum of snow relative reflectance was calculated using the average of the 30 snow spectra and the reference spectrum. The bare fore optic was mounted on a tripod at about $1 \mathrm{~m}$ height above the surface; therefore the footprint area of the spectroradiometer was a circle with a radius of about $22 \mathrm{~cm}$. During clear-sky days, measurements were taken between 1 and 4 times, when the solar zenith angle $\left(\theta_{0}\right)$ was between 50 and $60^{\circ}$. Apart from instrumental inaccuracy, potential error sources of the spec- 
tral reflectance measurement include variations in incident solar irradiance during the measurement time and deficiencies in the measurement method, which are discussed below.

For a correct measurement of the reference radiance, the reference Spectralon panel should be horizontally aligned, and should completely cover the $25^{\circ}$ field of view of the bare fore optic. Thus, the $12.5 \times 12.5 \mathrm{~cm}$ wide reference panel should be placed at a distance smaller than $28.2 \mathrm{~cm}$ from the bare fore optic and centred on its vertical projection. In our experiment, the horizontal levelling was checked through a bubble balancer, and the plate was manually held about $20 \mathrm{~cm}$ below the fore optic. However, the centring with respect to the vertical projection of the fore optic was done only visually (and, therefore, approximately). A first analysis of the data revealed a large positive bias in the VNIR snow reflectances, with a step-like drop of reflectance at the $1000 \mathrm{~nm}$ junction. We concluded that the reference panel did not completely cover the effective field of view (FOV) of the VNIR spectrometer, which is larger than the nominal FOV value given by the manufacturer (Mac Arthur et al., 2011). We therefore rejected all data at wavelengths smaller than $1000 \mathrm{~nm}$, and limited our analysis to the SWIR spectrum.

The small footprint area of the spectrometer on one hand ensured that the shadows of the instrument set-up and of the operator did not reach the target surface, but on the other hand amplified the impact of the possible roughness features and slopes on the measurements performed under clear skies (Pirazzini, 2004). A surface area as smooth as possible was chosen for each reflectance measurement, but the measured spot changed every time, as the surface needed to be undisturbed by previous measurements, and the chosen spots were often located over gentle dunes, which were free from roughness features (Fig. 3). Thus, a part of the difference between the measurements is most probably attributable to differences in the local slope. The surface tilting over these gentle snow dunes was very modest, usually between 0.5 and $2^{\circ}$. As we did not measure the surface tilting and its direction at each measurement spot, we calculated the surface tilting uncertainty applying Eq. (2) of Grenfell et al. (1994) assuming a tilt of $2^{\circ}$ and that the Sun was always in the uphill or downhill direction, maximizing the negative and positive errors respectively (Fig. 5). The estimated maximum error due to surface tilting $\left(\Delta_{\text {tilt }}\right)$ was therefore only a function of $\theta_{0}$, ranging between $+6 \%(+8 \%)$ in the downhill direction $\left(\Delta_{\text {tilt,down }}\right)$ and $-2 \%(-4 \%)$ in the uphill direction $\left(\Delta_{\text {tilt,up }}\right)$ at $\theta_{0}=50^{\circ}$ $\left(60^{\circ}\right)$.

The spread of the 30 consecutive snow reflectance spectra can evidence the possible change in solar illumination during the time interval of three minutes (revealing, for instance, the possible presence of thin cirrus in the solar direction). The repeatability error of the snow reflectance $\left(\sigma_{\mathrm{rpt}}\right)$ was calculated as the normalized standard deviation of reflectance among the 30 spectra. Excluding three wavebands with a very low signal to noise ratio $(1.33-1.6,1.8-2.1$, and $2.3-2.5 \mu \mathrm{m})$, $\sigma_{\text {rpt }}$ was within $\pm 0.6 \%( \pm 1.5 \%)$ in the SWIR1 (SWIR2)

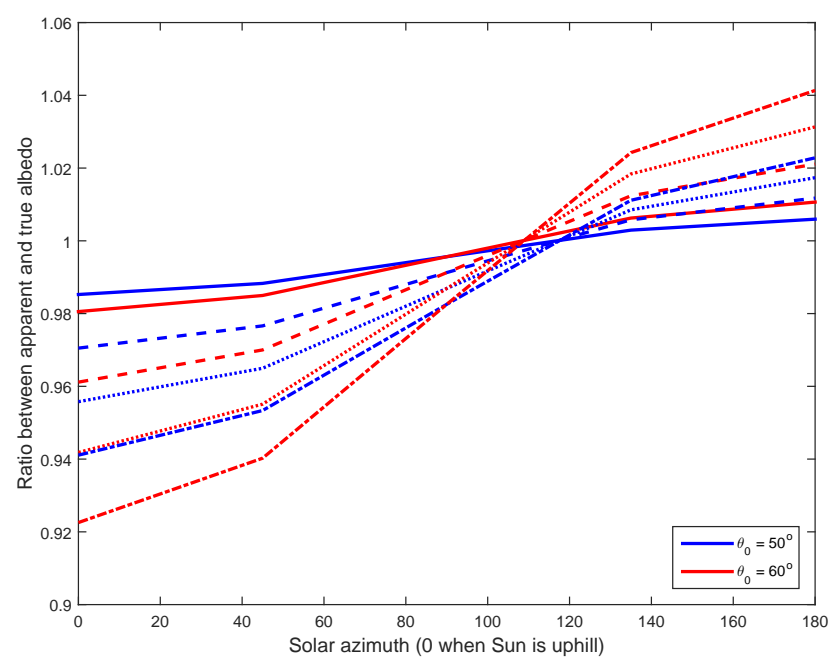

Figure 5. Ratio between apparent and true albedo calculated according to Eq. (2) in Grenfell et al. (1994) as a function of solar azimuth. Blue and red lines correspond to solar zenith angles $\left(\theta_{0}\right)$ of 50 and $60^{\circ}$, respectively. Surface slope angles of $0.5,1,1.5$, and $2^{\circ}$ are marked with continuous, dashed, dotted, and dashed-dotted lines, respectively.

wavelength region in most of the clear-sky cases, and within $\pm 2.0 \%( \pm 4.0 \%)$ on 5 and 6 January, where some thin cirrus were present, and during overcast conditions. These repeatability errors are consistent with the $\pm 2 \%$ ASD repeatability error found in well controlled laboratory and field experiments (Kuester et al., 2001) and in measurements of snow radiance over the Antarctic plateau (Hudson et al., 2006).

The repeatability error of the reference reflectance $\left(\sigma_{\text {ref }}\right)$, calculated as the normalized standard deviation of 30 consecutive spectra of reference reflectance, was $\pm 3 \%( \pm 4 \%)$ in the SWIR1 (SWIR2) wavelength region. This uncertainty is larger than $\sigma_{\mathrm{rpt}}$, and is presumably attributable to the inaccuracy of the manual horizontal levelling of the Spectralon plate.

Lastly, a possible error that is difficult to quantify is related to the presence of the operator. While the operator was always positioned opposite to the Sun's direction and therefore did not cast a shadow on the footprint area of the spectroradiometer, his presence caused a small reduction of the diffuse radiation reaching the area. In some cases the operator was closer to the reference panel than to the target area, causing a possible overestimation of the snow reflectance. Since in most days we measured several spectra a few hours apart, as a final quality criterion for our reflectance spectra, we selected only those spectra that lied in the range of uncertainty of the other spectra collected on the same day. A total of three spectra were discarded with this criterion. The analyzed spectra that fulfilled all quality criteria and were temporally closest to the snow pit measurements are listed in Table 1. 


\subsection{Sky spectral irradiance}

Before each set of reflectance spectra, 30 consecutive spectra of downward irradiance were collected, with the ASD cosine receptor fore optic pointing toward the zenith. These data were utilized to calculate the broadband surface albedo and the surface net shortwave radiation in Sect. 4.2. Excluding the wavebands with very low signal to noise ratio (see Sect. 2.5), the series of 30 consecutive spectra were overlapping within $\pm 0.5 \%$ in clear-sky conditions and \pm 0.7 and $\pm 2.4 \%$ in overcast conditions in the VNIR and SWIR regions, respectively. The cosine receptor utilized for the solar irradiance measurements does not have a perfect cosine response. For $\theta_{0}$ between 50 and $60^{\circ}$, the deviation of the cosine receptor from the pure cosine response is about $+10 \%$ in the VNIR region and lower than $+2 \%$ in the SWIR region (Carmagnola et al., 2013; Lubin and Vogelmann, 2011). Thus, the total error in the measured solar irradiance was in the range -1 to $+10 \%$ in the VNIR region, and in the range -1 to $+2 \%(-2$ to $+2 \%)$ in the SWIR region during clearsky (overcast) conditions.

\section{Methods of data analysis and modelling}

The content of Sects. 3 and 4 can be summarized as follows (see also Fig. 1): from the processing of the snow particle macro photos (Sect. 3.1) we obtained the vertical profiles of the particle metric distribution. These, together with the vertical profiles of $r_{\text {snow }}$, were used as input of the radiative transfer model DISORT to calculate the snow surface spectral albedo (Sect. 3.3). The surface albedo was also obtained from the measurements of surface nadir reflectance and a parameterization of the snow anisotropic reflectance factor (Sect. 3.2), and was used to validate the DISORT-derived surface albedo (Sect. 4.1). The broadband albedo and net shortwave radiation obtained from the measured and modelled spectral albedo were compared in Sect. 4.2. DISORT was then applied to the calculation of the optically equivalent particle radius $r_{\text {oeff }}$ based on the reflectance-derived spectral albedo, and the results were validated against the effective particle radius obtained from the metric distributions (Sect. 4.3). Finally, the sensitivity of $r_{\text {oeff }}$ to $r_{\text {snow }}$ and to the effective variance of the particle metric distribution (defined in Sect. 3.1.3) was explored (Sect. 4.4).

\subsection{Snow particle macro photos}

\subsubsection{Image enhancement and segmentation}

The original colour images had a resolution of $4272 \times 2848$ pixels for each of the three colour planes. The image processing was done applying the Matlab software. To improve the detection of the particle contour (image segmentation) two series of bi-cubical interpolation were applied (in each interpolation, each pixel resulted from the weighted average of the four neighbouring pixels in both $\mathrm{x}$ and $\mathrm{y}$ axes). This caused an image reduction of $1: 4$ leading the final images to have $1078 \times 712$ pixels. The images were then converted to greyscale followed by contrast adjustment and sharpening.

When choosing the image segmentation method, the general guideline that we followed was to obtain a black and white mask that is as faithful as possible to the image segmentation performed by the human brain. It is well known that human eyes and the human brain can segment an image better than any artificial intelligence. In order to achieve a sufficiently accurate result, we developed a segmentation procedure that requires a human control, as previously done by Pringle et al. (2009). The images were converted to binary black and white (bw) masks through two edge detection algorithms (one based on the Sobel method, and the other based on a threshold luminance). The detected snow particles in the two binary masks were then dilated, the interior gaps were filled, and finally the snow particles were smoothed out to the original size. To allow reasonable image quantification, snow particles composed of less than 20 pixels were eliminated, and all snow particles connected to the edge of the image and therefore not entirely included in the image were automatically masked out.

The key step of this image processing procedure is the choice of the proper settings. For each image, the combination of the allowed settings (contrast adjustment, edge detection algorithm, grey threshold, dilation/erosion radius, minimum number of pixels per detected particle) that generated the bw mask closest to the visual segmentation was chosen. The manual setting of the parameters can introduce a certain level of subjectivity in the analysis, discussed in Sect. 3.1.3. The false snow particles (i.e. water droplets or dirtiness detected as snow particles) and misrepresented snow particles (in shape or size) that occasionally still remained in the final mask were singularly removed. Figure 6a shows an example of a segmented image.

An artefact of the particle detection method is that snow particles very close to each other were not distinguished and were identified as single particles. However, the biggest clusters were often connected to the border and were therefore automatically eliminated. The magnification was not adjusted for each image; therefore, the samples characterized by small particles contained a larger population than the samples with large particle sizes. This has an impact on the representativeness of the samples (see Sect. 3.1.3), which is higher for populations of small snow particles.

\subsubsection{Image quantification and definition of particle metric}

The final images contained the 2-D projections of the sampled snow particles, with an image resolution (i.e., pixel size) that varied between 0.008 and $0.014 \mathrm{~mm}$. For each particle, we determined the skeleton by successively removing pixels on the boundary, without letting the particle break apart 


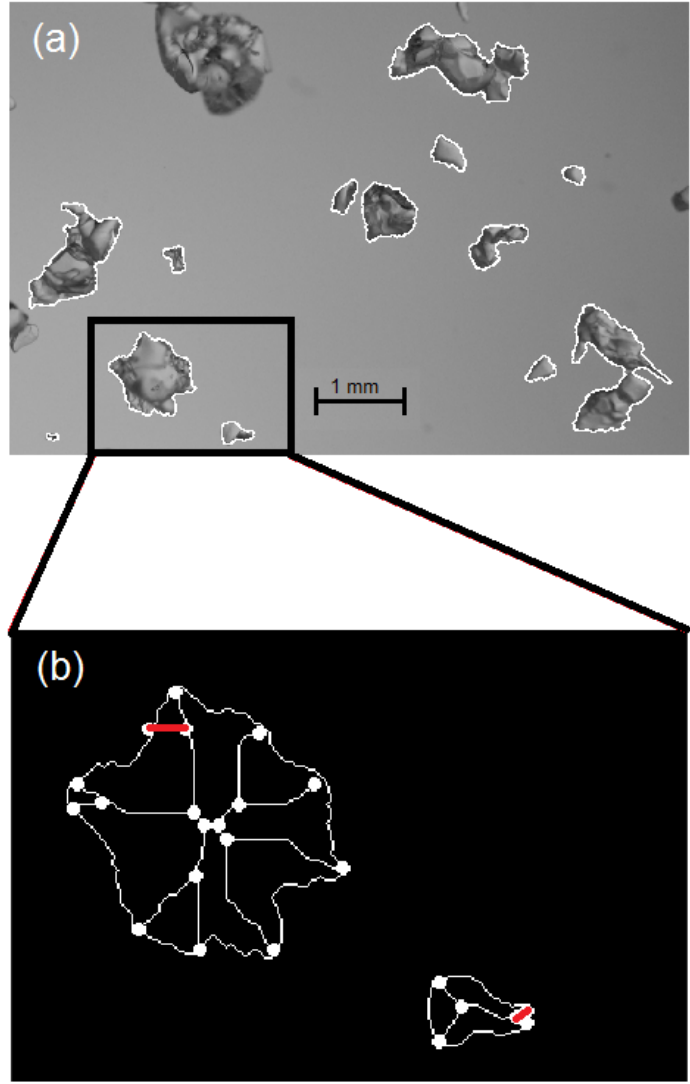

Figure 6. Example of a segmented image from 29 December 2009: the segmented outlines are overlaid with the original image (a), and two detected particles are magnified (b) to illustrate the skeleton (inner white lines), the skeleton endpoints (white dots at the particle border), and branch points (white dots along the junction nodes of the skeletons). The shortest of the skeleton branches, defined here as the Euclidean distances between endpoints and nearest branch point, are marked in red and correspond to the SSK metric.

(using the automatic routine "bwmorph" of the Matlab Image Processing Toolbox). Endpoints and branch points were then identified as the extremities and the junction nodes of the skeleton branches, respectively (Fig. 6b). We calculated the lengths of skeleton branches as the Euclidean distances between the skeleton's endpoints and their nearest branch points, and we selected the shortest skeleton branch (SSK) as the particle metric (Fig. 6b). In practice, we expect SSK to be a close approximation of half the width of the shortest particle dimension, which has shown the best match with $r_{\text {oeff }}$ (Aoki et al., 1998, 2000, 2003).

The number and location of the skeleton's endpoints is affected by the image segmentation: smoother contours result in fewer endpoints while edged contours produce more of them. However, the settings in the image processing procedure were adjusted so that shape and contour distortions were minimized, or badly contoured particles were eliminated. Endpoints are also affected by how well the details of shape are resolved in the digital photo. If the image resolution is lower than the dimension of the particle details, the location and the number of endpoints will be erroneous. In our case, the final resolution was of the same order of magnitude as that of the smallest possible snow particle dimension (Liou et al., 2008); therefore we believe that the endpoints were rather well identified.

\subsubsection{Effective radius and effective variance of the particle metric distribution}

One objective of our study is to relate the particle metric distributions obtained from the macro photos to the $r_{\text {oeff }}$ derived from the surface spectral albedo. For radiative transfer calculations, Hansen and Travis (1974) defined the effective radius $r_{\text {eff }}$ of an ensemble of spheres as the area-weighted mean radius of the distribution of scattering particles:

$r_{\mathrm{eff}}=\frac{\sum r_{i}^{3}}{\sum r_{i}^{2}}$

where $r_{i}$ is the radius of the $i$ th particle. This concept rose from the consideration that each particle scatters an amount of light proportional to its geometric cross-sectional area (i.e. projected area). Furthermore, as a measure of the width of the size distribution, the effective variance $v_{\text {eff }}$ was defined as (Hansen and Travis, 1974; Chýlek et al., 1992):

$v_{\mathrm{eff}}=\frac{\sum\left[\left(r_{i}-r_{\mathrm{eff}}\right)^{2} r_{i}^{2}\right]}{r_{\mathrm{eff}}^{2} \sum r_{i}^{2}}=\frac{m_{4} m_{2}}{m_{3}^{2}}-1$,

where $m_{2}, m_{3}$, and $m_{4}$ are the second, third, and fourth moments of the particle size distribution. For our measured SSK distributions, we calculated $r_{\text {eff }}$ and $v_{\text {eff }}$ by interpreting $r_{i}$ in Eqs. (2) and (3) as the dimension of the $i$ th particle according to the SSK metric.

\subsubsection{Uncertainties in measured particle metrics}

Throughout this paper, uncertainty in $r_{\mathrm{eff}}$ and $v_{\mathrm{eff}}$ (and albedo) is estimated in terms of the " 5 and $95 \%$ errors" (E05 and E95, respectively). The $5 \%$ (95\%) error is defined as the difference between the lower (upper) limit of the $90 \%$ confidence interval and the best estimate. We consider here two sources of errors in the obtained SSK distributions: one due to the subjective choice of the setting parameters in the image segmentation procedure, and the other due to the representativeness of the measured samples.

To estimate the first uncertainty, the segmentation procedure was applied by three different persons (two of whom without any previous experience on image processing) on a subset of three samples. The "subjectivity errors" of the $r_{\text {eff }}$ and $v_{\text {eff }}$ obtained from the metric distributions were calculated as the relative root-mean-square difference between the metric obtained by one experienced and two unexperienced 
persons in image processing. The 5 and $95 \%$ subjectivity errors applied to all studied cases $\left(\mathrm{E} 05_{\text {sub }}\right.$ and $\mathrm{E} 95_{\text {sub }}$, respectively) were estimated by averaging the errors of the two unexperienced persons over the three sampled cases and multiplying by the coefficient $c=1.6456$ (see also Appendix A).

The "representativeness errors" indicate how well the measured samples represent the real distribution of snow particles in the field. Each of our snow samples included different numbers of snow particles, ranging from about 40 (in the case of very large particles) to some hundreds (in the case of small particles). Assuming that the measured samples are random and unbiased, the uncertainty related to the limited population can be calculated using bootstrap resampling. For each sample, we generated 10 thousand random realizations of the original distribution. Depending on whether the error in $r_{\text {eff }}$ or $v_{\text {eff }}$ was considered, the realizations were ordered according to their $r_{\text {eff }}$ or $v_{\text {eff }}$, and the values of $r_{\text {eff }}$ or $v_{\text {eff }}$ corresponding to the 5th and 95th percentile of the population were used to define the respective 5 and $95 \%$ errors (E05 ${ }_{\mathrm{rpr}}$ and $\mathrm{E} 95_{\mathrm{rpr}}$ ).

The total uncertainty on the metric distributions (in the form of 5 and $95 \%$ errors) is given by the square root of the sum of the squared subjectivity and representativeness errors.

\subsection{Surface spectral albedo}

In this study, we utilize the measured snow nadir reflectance to verify the reflectance simulated by a radiative transfer model that applies the snow observations (particle size distribution and density). We also derive the optical effective radius $r_{\text {oeff }}$, which will be compared with the $r_{\text {eff }}$ obtained from macro photos. In general, $r_{\text {oeff }}$ can be obtained from the snow reflectance at specific wavelengths/wavebands and viewing angles, measured from remote sensing or in situ sensors (e.g. Kokhanovsky et al., 2011; Painter et al., 2007). Alternatively, the snow spectral albedo $\alpha$ (i.e. the reflectance integrated over the hemisphere) is used, as in the case of the DUal Frequency Integrating Sphere for Snow SSA measurement (DUFISSS, Gallet et al., 2009) or the Alpine Snowpack Specific Surface Area Profiler (ASSSAP, Arnaud et al., 2011). We chose to use use $\alpha$, as it is more directly applicable to surface energy budget calculations than the reflectances.

To get $\alpha$, we divided the measured $I_{\mathrm{n}}$ by the anisotropic reflectance factor $(\Phi)$, which was extracted from the measurements of Hudson et al. (2006) at Dome Concordia, over the Antarctic Plateau. The applied procedure is described in detail in Appendix B. The 5 and $95 \%$ errors of $\alpha$ introduced by the parameterization of $\Phi\left(\mathrm{E} 05_{\Phi}^{2}\right.$ and $\mathrm{E} 95_{\Phi}^{2}$, respectively) were $\pm 7 \%$. The total 5 and $95 \%$ errors of $\alpha$ calculated according to Eqs. (A1) and (A2) in Appendix A and averaged over the examined cases are listed in Table 4.
Table 4. Total 5 and $95 \%$ errors of $\alpha$ (in percentages) calculated according to Eqs. (A1) and (A2) in Appendix A, averaged over the examined clear and overcast days.

\begin{tabular}{lrrrrrr}
\hline & \multicolumn{2}{c}{$\lambda<1.8 \mu \mathrm{m}$} & & \multicolumn{2}{c}{$\lambda>1.8 \mu \mathrm{m}$} \\
\cline { 2 - 3 } \cline { 5 - 6 } & $5 \%$ & $95 \%$ & & $5 \%$ & $95 \%$ \\
\hline Clear-sky days & -9 & +11 & & -11 & +13 \\
Overcast days & -9 & +9 & & -11 & +12 \\
\hline
\end{tabular}

\subsection{Modelling strategy}

For comparison with the measurements, spectral surface albedos were computed using DISORT (Stamnes et al., 1988), with 32 streams and $\delta$-M-scaling (Wiscombe, 1977) included. Two snow crystal shape assumptions were considered: (1) spheres, and (2) severely roughened (SR) droxtals. Droxtals are polyhedra with 20 faces, whose singlescattering properties (SSPs) have been found to well represent the small ice crystals in clouds (Yang et al., 2003). The SSPs of spheres (extinction efficiency $Q_{\text {ext }}$, single-scattering albedo $\omega$ (or co-albedo $1-\omega$ ), and asymmetry parameter $(g$ ) were computed using Mie theory (Bohren and Huffman, 1983), while for droxtals, the database of Yang et al. (2013) was used. In both cases, the refractive index of ice is based on Warren and Brandt (2008).

While spheres have been frequently used in radiative transfer applications involving snow, it is well known that they do not represent well the SSPs of non-spherical particles such as snow grains. A common feature for most non-spherical shapes, including SR droxtals, is that sideward scattering is stronger than for spheres, and therefore, the asymmetry parameter $g$ is smaller. In fact, out of the non-spherical shapes considered by Yang et al. (2013), droxtals have the second lowest $g$ (after aggregates of columns). Furthermore, the value of $\mathrm{g}$ for droxtals agrees closely with measurements conducted for blowing snow at $\lambda=0.8 \mu \mathrm{m}$ (Räisänen et al., 2015). This makes droxtals a reasonable first guess when representing the effects of snow grain non-sphericity on snow albedo. It is, however, clear that the observed shapes of snow grains rarely resemble droxtals (or any other single idealized shape), and therefore, the present calculations should rather be viewed as a sensitivity test than as a rigorous treatment of snow grain non-sphericity.

The behaviour of $g$ and 1- $\omega$ for spheres and droxtals is compared in Fig. 7 for the wavelength range $\lambda=1.0-2.5 \mu \mathrm{m}$ considered in this study. Indeed, $g$ is considerably smaller for SR droxtals than for spheres especially at relatively weakly absorbing wavelengths (e.g. $g \approx 0.78$ vs. $g \approx 0.89$ at $\lambda=$ $1.0 \mu \mathrm{m}$ ), while $1-\omega$ is slightly larger for droxtals. Figure 7 also shows how both $g$ and 1- $\omega$ increase with increasing snow particle size, which explains the well-known fact that snow albedo decreases with increasing particle size. Due to their smaller $g$, for a given snow particle size, snow albedo 

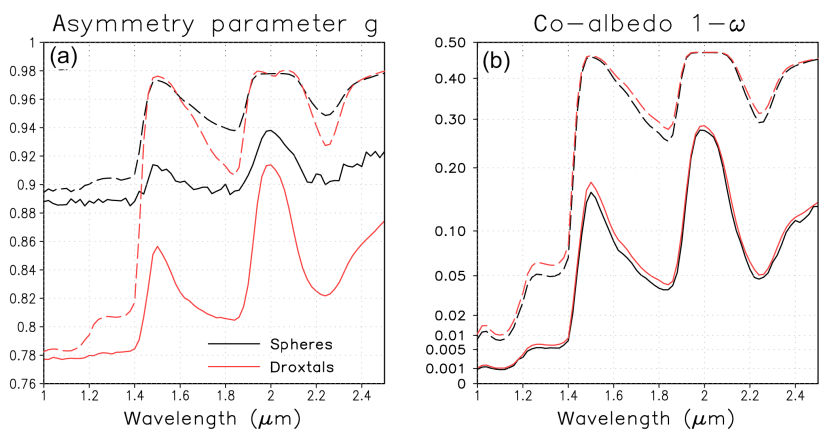

Figure 7. (a) Asymmetry parameter $g$ and (b) single-scattering coalbedo 1- $\omega$ for spheres (black lines) and severely roughened droxtals (red lines), for two values of volume-to-projected area equivalent radius: $r_{\mathrm{VP}}=50 \mu \mathrm{m}$ (solid lines) and $r_{\mathrm{VP}}=500 \mu \mathrm{m}$ (dashed lines).

is higher when droxtals rather than spheres are used to represent the SSPs. Equivalently, a larger snow particle size is needed for droxtals than for spheres to fit the observed albedo.

When modelling surface albedo, snow is considered pure, as soot concentration in Antarctica is so low as to be optically insignificant (Warren and Clarke, 1990). Moreover, the $r_{\text {eff }}$ obtained from the SSK metric distribution is interpreted as the volume-to-projected area equivalent radius $r_{\mathrm{VP}}$ of either spheres or droxtals. The optical properties of a snow layer with density $\rho_{\text {snow }}$ and thickness $\Delta z$, that is, the optical thickness $\tau$ and layer-mean single-scattering albedo $\omega$ and asymmetry parameter $\bar{g}$, are computed through summation over the observed discrete particle size distribution:

$\tau=\rho_{\text {snow }} \Delta z \frac{\sum_{i} Q_{\text {ext }}\left(r_{i}\right) \pi r_{i}^{2}}{\rho_{\text {ice }} \sum_{i} 4 / 3 \cdot \pi r_{i}^{3}}$,

$\bar{\omega}=\frac{\sum_{i} Q_{\mathrm{ext}}\left(r_{i}\right) \omega\left(r_{i}\right) \pi r_{i}^{2}}{\sum_{i} Q_{\mathrm{ext}}\left(r_{i}\right) \pi r_{i}^{2}}$,

$\bar{g}=\frac{\sum_{i} Q_{\mathrm{ext}}\left(r_{i}\right) \omega\left(r_{i}\right) g\left(r_{i}\right) \pi r_{i}^{2}}{\sum_{i} Q_{\mathrm{ext}}\left(r_{i}\right) \omega\left(r_{i}\right) \pi r_{i}^{2}}$.

Here, $\rho_{\text {ice }}=916.7 \mathrm{~kg} \mathrm{~m}^{-3}$ is the density of pure ice, and $Q_{\text {ext }}\left(r_{i}\right), \omega\left(r_{i}\right)$ and $g\left(r_{i}\right)$ are the extinction efficiency, singlescattering albedo and asymmetry parameter of a sphere or a droxtal with $r_{\mathrm{VP}}=r_{i}$. Wavelength dependence is not marked explicitly. In addition to the calculations using the observed size distributions, some calculations using either a monodisperse or lognormal size distribution are performed. In fact, the exact shape of the size distribution has little impact insofar the effective radius and effective variance are fixed (Chýlek et al., 1992; Hansen and Travis, 1974).
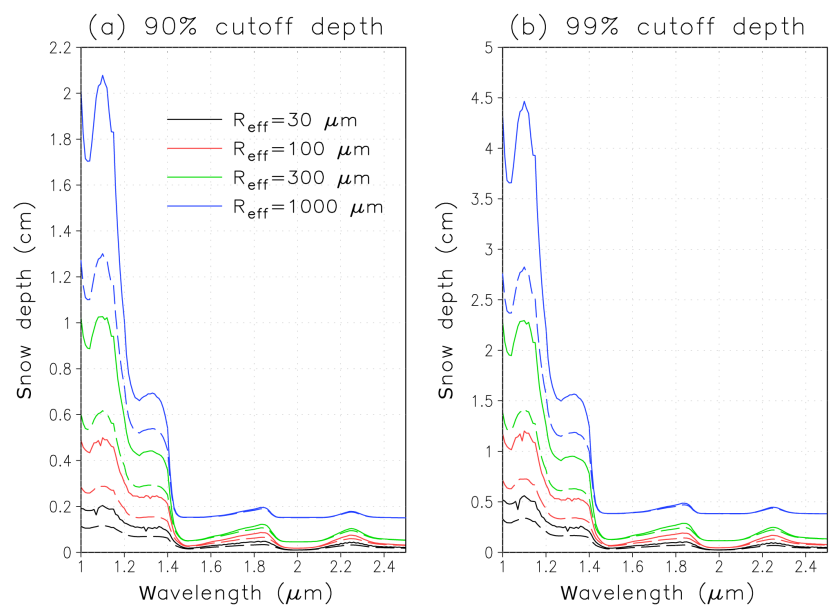

Figure 8. Spectral $90 \%$ (a) and $99 \%$ (b) cutoff depth of the semiinfinite albedo in the SWIR region for diffuse incident radiation. Snow density is $400 \mathrm{~kg} \mathrm{~m}^{-3}$. The cases of effective particle radius of $0.03,0.1,0.3$, and $1 \mathrm{~mm}$ (black, red, green, and blue lines, respectively) are illustrated for the assumption of spherical shapes (continuous lines) and droxtal shapes (dashed lines), for a mono-disperse size distribution.

In all the calculations reported here, the HenyeyGreenstein approximation (Henyey and Greenstein, 1941) is used for the scattering phase function. On one hand, based on comparisons with a measured phase function for blowing snow (Räisänen et al., 2015), it is unlikely that droxtals (let alone spheres) would represent the phase function of snow particles accurately. On the other hand, in line with the findings of Boucher (1998) for aerosol radiative forcing (Fig. 6 in that paper), the differences in snow albedo computed with the full phase function and the Henyey-Greenstein phase function are small at the intermediate solar zenith angles $\left(\theta_{0} \approx 50-60^{\circ}\right)$ considered here (in fact, generally below 0.01 for both droxtals and spheres). Finally, out of the 8 days considered, the incoming radiation at the surface is assumed to be diffuse for the 2 overcast days (23 December and 14 January), while for the other (cloud-free) days, parallel solar radiation is assumed.

The calculation of $r_{\text {oeff }}$ was done by applying the surface albedo spectra (described in Sect. 3.2), the measured $\rho_{\text {snow }}$ (described in Sect. 2.1), and the $v_{\text {eff }}$ of the SSK metric distribution. The sensitivity of the modelled $r_{\text {oeff }}$ to $\rho_{\text {snow }}$ and $v_{\text {eff }}$ is discussed in Sect. 4.3.

In order to facilitate the interpretation of our results, we estimated with DISORT the depths at which the snowpack is optically semi-infinite, in the range of analyzed wavelengths $(1.0-2.5 \mu \mathrm{m})$. In particular, following Zhou et al. (2003) we calculated the snow depths required for the albedo to reach 90 and $99 \%$ of the semi-infinite albedo (called 90 and $99 \%$ cutoff depths, respectively). Figure 8 shows the spectral $90 \%$ (left panel) and $99 \%$ (right panel) cutoff depths in the SWIR region for diffuse incident radiation, applying a snow den- 

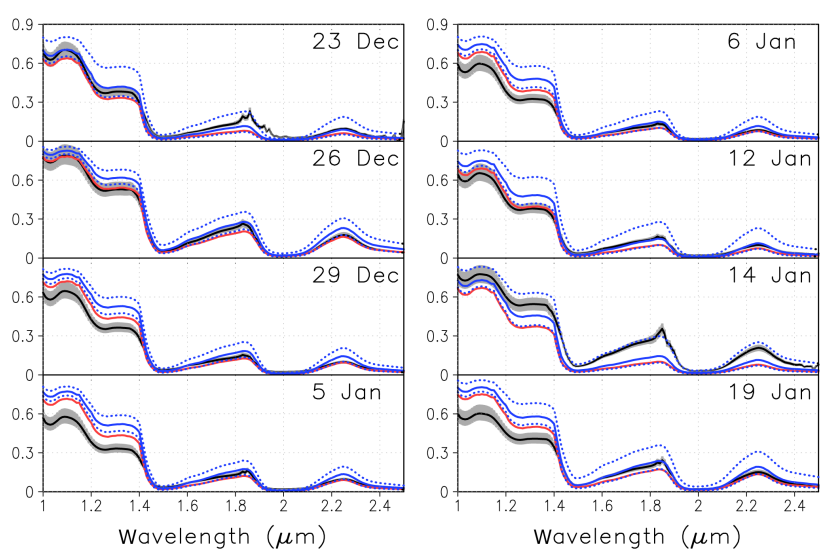

Figure 9. Spectral snow albedo obtained from reflectance measurements (black line) and calculated with DISORT using spherical particle shapes (red line) and droxtal particle shapes (blue line) for all case studies. In the model calculations, we applied the observed snow density and the grain distribution based on the SSK metric. The grey shaded areas mark the total uncertainties on the albedo derived from reflectance observations (Eqs. (A1) and (A2) in Appendix A), while the blue dotted lines represent the uncertainty in the droxtal model calculations due to the uncertainty in the metric distributions (Eqs. (A3) and (A4) in Appendix A). For the calculations with spheres, the magnitude of uncertainty is comparable to the uncertainty in the droxtal calculations (not shown).

sity of $400 \mathrm{~kg} \mathrm{~m}^{-3}$. The cases of the effective particle radius of $0.03,0.1,0.3$, and $1 \mathrm{~mm}$ are illustrated for the assumption of spherical shapes (continuous lines) and droxtal shapes (dashed lines). Figure 8 reveals the progressive decrease of cutoff depths with increasing wavelength, as observed in Zhou et al. (2003): for the intermediate particle radii considered here $(0.1$ and $0.3 \mathrm{~mm})$, the $90 \%$ cutoff depth is $\sim 3-10 \mathrm{~mm}$ at the shortest SWIR, and becomes less than $1 \mathrm{~mm}$ at the longest SWIR. In the case of near-surface density around $200 \mathrm{~kg} \mathrm{~m}^{-3}$ as observed on 19 January (Fig. 2b), the cutoff depths are double compared to the values shown in Fig. 8. In all cases, even the $99 \%$ cutoff depth does not exceed $5 \mathrm{~cm}$, and therefore, we limited our analyses to the snow properties observed in the uppermost $5 \mathrm{~cm}$.

\section{Results}

\subsection{Spectral albedo obtained from reflectance measurements and calculated on the basis of the SSK metric}

Figure 9 illustrates, for the eight case studies, the spectral snow albedo obtained from the reflectance measurements, together with the albedo modelled based on the SSK metric. The overcast cases (23 December and 14 January) were both preceded by snowfall events, but the albedo on 23 December was lower than on 14 January. The highest albedo during
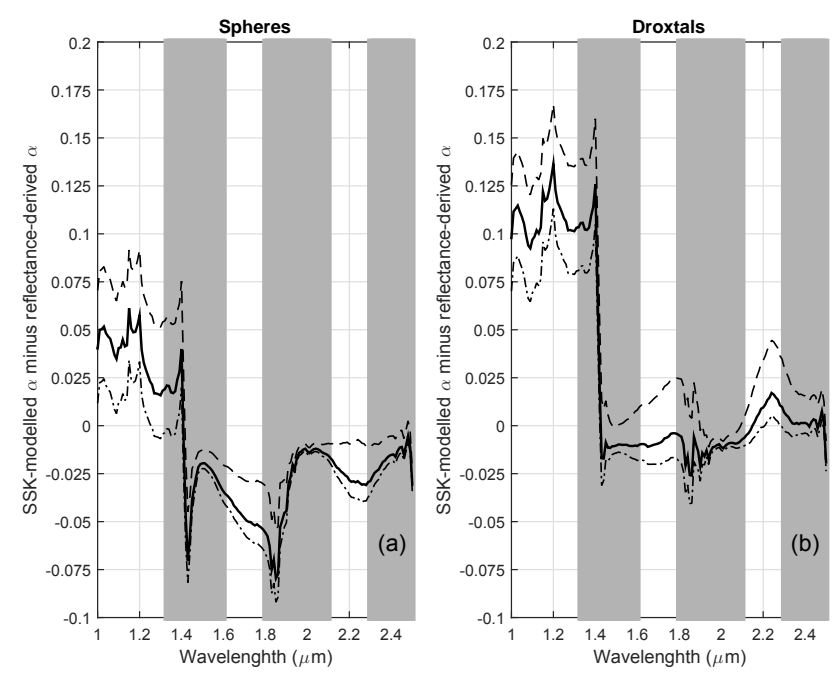

Figure 10. Mean difference between model- and reflectancederived albedo for spherical (a) and droxtal (b) particle shape. Shaded areas correspond to wavebands where the signal-to-noise ratio of the reflectance measurements was very low. Dashed black lines mark the 5 and $95 \%$ confidence limits of the mean bias (see Appendix A3).

our measurement campaign was observed on 26 December, in correspondence with the finest surface snow generated by a snowdrift event. Our successive albedo spectra until 6 January revealed a progressive albedo decrease associated with the snow ageing. On 12 January, albedo slightly increased for $\lambda<1.4 \mu \mathrm{m}$, as a result of a change in the composition of the snow crystal population at the surface: in addition to the rounded polycrystals typical of 5 and 6 January, also faceted surface hoar was present (see Sect. 2.3). In the last two case studies (14 and 19 January), albedo was higher than on 5 and 6 January at almost all wavelengths, as a consequence of the light snowfall during the previous days.

Mean differences between modelled and observed albedo values are shown in Fig. 10. For droxtals, the modelled albedo is in a good agreement with the observed albedo values for $\lambda>1.4 \mu \mathrm{m}$ (Fig. 10b). The biases are small, and considering the impact of sampling and image processing uncertainty, the computed values agree with the observations in all case studies in Fig. 9. For shorter SWIR wavelengths, the modelled albedo applying droxtal shapes fits best the observation-based albedo on 23 and 26 December, but generally overestimates it, especially on 5 and 6 January (Fig. 9). Only on 14 January the modelled albedo tends to underestimate the observations at all wavelengths. Spherical shapes underestimate the albedo for $\lambda>1.4 \mu \mathrm{m}$ but produce a better match with the measurement-derived albedo than droxtal shapes for $\lambda<1.4 \mu \mathrm{m}$, although both have a positive bias in this wavelength range (Fig. 10). The reason for these case and wavelength-dependent differences between modelled and measured albedo is addressed in Sect. 5.3. 
Table 5. Mean surface albedo $\left(\overline{\alpha_{\mathrm{b}, \Delta \lambda}}\right)$ and net shortwave radiation $\left(\overline{\operatorname{Swn}_{\Delta \lambda}}, \mathrm{W} \mathrm{m}^{-2}\right)$ integrated over three distinct wavebands $(\Delta \lambda=1.0-$ $1.4,1.4-2.5$, and 1.0-2.5 $\mu \mathrm{m}$ ) during overcast and clear-sky conditions. "Obs" refers to values obtained using the reflectance-derived albedo, "Bias S" and "Bias D" are the mean biases between model- and reflectance-derived integrated quantities obtained using spheres and droxtals, respectively.

\begin{tabular}{|c|c|c|c|c|c|c|c|}
\hline & \multirow[b]{2}{*}{$\Delta \lambda(\mu \mathrm{m})$} & \multicolumn{3}{|c|}{ Overcast } & \multicolumn{3}{|c|}{ Clear-sky } \\
\hline & & Obs & Bias $S$ & Bias D & Obs & Bias $S$ & Bias D \\
\hline & $1.0-1.4$ & 0.62 & -0.08 & -0.01 & 0.53 & 0.07 & 0.14 \\
\hline \multirow[t]{3}{*}{$\overline{\alpha_{\mathrm{b}, \Delta \lambda}}$} & $1.4-2.5$ & 0.12 & -0.07 & -0.04 & 0.08 & -0.02 & 0 \\
\hline & $1.0-2.5$ & 0.51 & -0.08 & -0.02 & 0.37 & 0.04 & 0.09 \\
\hline & $1.0-1.4$ & 19 & 4 & 1 & 48 & -7 & -15 \\
\hline \multirow[t]{2}{*}{$\overline{\operatorname{Swn}_{\Delta \lambda}}$} & $1.4-2.5$ & 13 & 1 & 1 & 55 & 1 & 0 \\
\hline & $1.0-2.5$ & 32 & 6 & 1 & 104 & -6 & -15 \\
\hline
\end{tabular}

\subsection{Surface broadband albedo and net shortwave radiation}

To examine the impact of the bias in the modelled albedo (Fig. 10) on the surface net shortwave radiation, we calculated the broadband surface albedo $\left(\alpha_{\mathrm{b}}\right)$ and broadband net shortwave radiation (Swn) in the whole solar spectrum $(0.35-2.5 \mu \mathrm{m})$ and in three distinct bands: $1.0-1.4 \mu \mathrm{m}$ (where we got the largest albedo biases), 1.4-2.5 $\mu \mathrm{m}$ (where we got the smallest albedo biases), and the whole interval 1.0-2.5 $\mu \mathrm{m}$ used in spectral albedo analysis. The broadband downward irradiance was computed from the measurements of spectral downward irradiance (Sect. 2.6), while the upward irradiance was derived by multiplying the downward irradiance by the albedo computed using droxtals (for $\lambda=0.35-2.5 \mu \mathrm{m}$ ) and spheres (for $\lambda=1.0-2.5 \mu \mathrm{m}$ ) and by the spectral albedo obtained from reflectance measurements (for $\lambda=1.0-2.5 \mu \mathrm{m}$ ). The measurement- and model-derived broadband values are compared in Table 5 for the three wavebands mentioned above, while the droxtal-modelled broadband values encompassing the solar spectrum $(0.35-2.5 \mu \mathrm{m})$ are used here only for evaluating the fractional contributions of each waveband.

First, we note that the spectral partitioning of solar energy absorbed by snow differs greatly from that of the incoming irradiance. On average, in the clear-sky (overcast) cases $80 \%$ (66\%) of the net shortwave radiation absorbed by the snow belonged to the 1.0-2.5 $\mu$ m waveband, which contributed $23 \%(14 \%)$ of the incoming irradiance, and $50 \%$ ( $28 \%$ ) of the net shortwave radiation belonged to the 1.4$2.5 \mu \mathrm{m}$ waveband, which contributed only $9 \%$ (3\%) of the incoming irradiance. The disproportionally large contribution of the SWIR bands to the net radiation results, of course, from the snow albedo being much lower than in the VNIR region. Furthermore, in the clear-sky cases, the 1.4-2.5 $\mu \mathrm{m}$ region made the largest contribution to the absorbed shortwave energy $(50 \%)$, while in the overcast cases the largest contribution (roughly $38 \%$ ) came from the $1.0-1.4 \mu \mathrm{m}$ region. This occurs because clouds selectively absorb the shortwave radiation at the longest wavelengths and therefore shift the spectral distribution of irradiance toward the visible region.

Table 5 lists the mean surface albedo $\left(\overline{\alpha_{\mathrm{b}, \Delta \lambda}}\right)$ and net shortwave radiation $\left(\overline{\mathrm{Swn}_{\Delta \lambda}}, \mathrm{W} \mathrm{m}^{-2}\right)$ integrated over three distinct wavebands (1.0-1.4, 1.4-2.5, and 1.0-2.5 $\mu \mathrm{m})$ during overcast and clear-sky conditions, together with the biases between model- and reflectance-based averages. As expected, the modelled $\overline{\alpha_{\mathrm{b}, 1.0-1.4}}$ using droxtals showed the largest positive albedo bias in the clear-sky cases. As the bias in $\overline{\alpha_{\mathrm{b}, 1.4-2.5}}$ was minimal, the bias of 0.09 in $\overline{\alpha_{\mathrm{b}, 1.0-2.5}}$ was almost totally due to the bias in $\overline{\alpha_{\mathrm{b}, 1.0-1.4}}$. This positive albedo bias produced a negative bias of $-15 \mathrm{~W} \mathrm{~m}^{-2}$ in $\overline{\mathrm{Swn}}_{1.0-2.5}$. However, it should be kept in mind that in the computation of the broadband albedo $\alpha_{\mathrm{b}}, \overline{\alpha_{\mathrm{b}, 1.0-2.5}}$ is weighted by the corresponding fraction of incoming irradiance, which is only $23 \%$. Since in the visible region the albedo sensitivity to snow particle size is small, we presume that the bias in the modelled $\alpha_{\mathrm{b}}$ is much more modest than in the $1.0-2.5 \mu \mathrm{m}$ region. In overcast conditions, the mean bias in the droxtal based $\overline{\alpha_{\mathrm{b}, 1.0-2.5}}$ was minimal, and, consequently, the corresponding bias in $\overline{\mathrm{Swn}_{1.0-2.5}}$ was negligible. Overall, spherical particles caused smaller $\overline{\alpha_{\mathrm{b}, \Delta \lambda}}$ biases than droxtal particles in the clear-sky cases, because of the smaller positive bias in the $1.0-1.4 \mu \mathrm{m}$ region. The biases in the sphere-based $\overline{\alpha_{\mathrm{b}, \Delta \lambda}}$ and in the associated $\overline{\operatorname{Swn}_{\Delta \lambda}}$ are in qualitative agreement with the biases obtained by Carmagnola et al. (2013) using the same modelling approach, although Carmagnola et al. (2013) showed the albedo and the absorbed energy integrated over different wavebands and therefore a direct quantitative comparison is not possible.

\subsection{Comparison between measured $r_{\text {eff }}$ and optically equivalent $r_{\text {oeff }}$}

Figure 11 shows $r_{\text {eff }}$ at the surface ( $r_{\text {eff,sur }}$, red circles) and at $5 \mathrm{~cm}$ depth ( $r_{\text {eff, } 5 \mathrm{~cm}}$, green circles), calculated according to

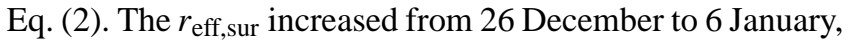
and then it remained almost constant. Its range of variability was from $0.07 \pm 0.01$ to $0.2 \pm 0.1 \mathrm{~mm}$. The mean relative 

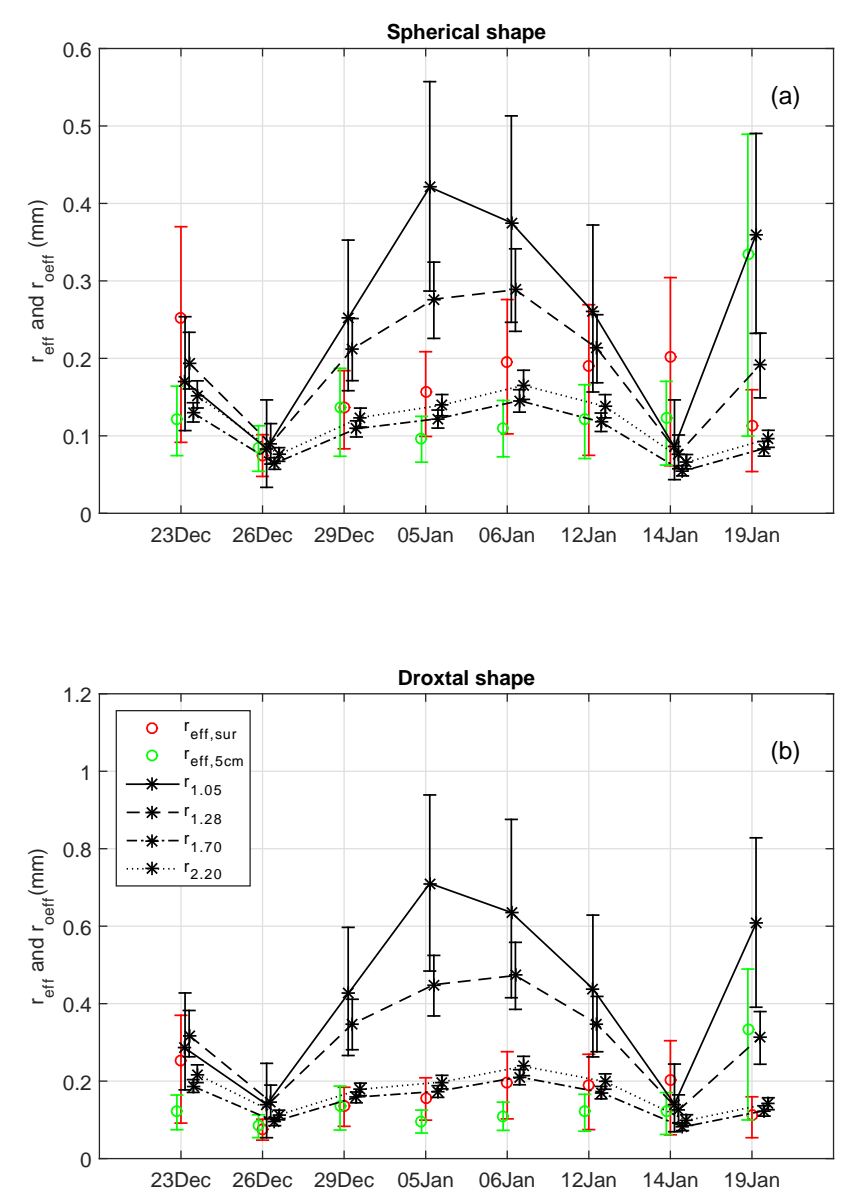

Figure 11. $r_{\text {eff }}$ obtained from the distributions of shortest skeleton branches at the surface ( $r_{\text {eff,sur }}$, red circles) and at $5 \mathrm{~cm}$ depth ( $r_{\text {eff, } 5 \mathrm{~cm}}$, green circles), and $r_{\text {oeff }}$ derived with DISORT from spectral albedo observations at the wavebands centred on 1.05, 1.28, 1.70 , and $2.20 \mu \mathrm{m}$ (stars with continuous, dashed, dashed-dotted, and dotted lines, respectively) during the eight case studies, for spherical (a) and droxtal (b) particle shapes. Error bars represent the uncertainties in the data and in the model calculations: for $r_{\mathrm{eff}, \mathrm{sur}}$ and $r_{\text {eff, }} 5 \mathrm{~cm}$, the uncertainty is calculated according to Eqs. (A3) and (A4) in Appendix A, while for $r_{1.05}, r_{1.28}, r_{1.70}$, and $r_{2.20}$ the uncertainty results from the propagation of the errors in the particle metrics to the modelled albedo (E05 $\alpha$, mod and E95 $5_{\alpha, \text { mod }}$ described in Appendix A3).

(i.e. fractional) 5 and $95 \%$ subjectivity (representativeness) errors of $r_{\text {eff,sur }}$ (defined in Sect. 3.1.4) were $\pm 11 \%$ ( -15 and $+10 \%)$. The values of $r_{\text {eff }, 5 \mathrm{~cm}}$ were mostly lower than those

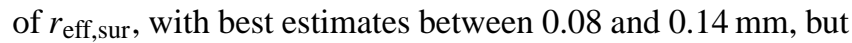
attained a high value of $0.3 \pm 0.2 \mathrm{~mm}$ on 19 January. The effective variance $v_{\text {eff }}$, calculated according to Eq. (3), was larger at the surface than at $5 \mathrm{~cm}$ depth (not shown), as expected considering the various mechanisms of crystal formation, fragmentation, aggregation, and metamorphism occurring at the surface. $v_{\text {eff }}$ at the surface tended to increase from roughly 0.2 in the beginning of the period to 0.5 near
Table 6. Mean optical effective radius $\left(\overline{r_{\text {oeff }}}, \mathrm{mm}\right)$ obtained from the measurement-derived surface albedo at four $0.1 \mu \mathrm{m}$-wide wavebands centred at $1.05,1.28,1.70$, and $2.20 \mu \mathrm{m}$. The effective variance used in the model calculations is that at the surface layer. The standard deviation of $r_{\text {oeff }}$ among the eight case studies is given in parentheses.

\begin{tabular}{|c|c|c|}
\hline $\begin{array}{l}\text { Central } \\
\text { wavelength } \\
(\mu \mathrm{m})\end{array}$ & $\begin{array}{c}\overline{r_{\text {oeff }} \text { for }} \\
\text { spherical } \\
\text { shape } \\
(\mathrm{mm})\end{array}$ & $\begin{array}{c}\overline{r_{\text {oeff }} \text { for }} \\
\text { droxtal } \\
\text { shape } \\
(\mathrm{mm})\end{array}$ \\
\hline 1.05 & $0.26(0.12)$ & $0.43(0.21)$ \\
\hline 1.28 & $0.20(0.07)$ & $0.32(0.11)$ \\
\hline 1.70 & $0.11(0.03)$ & $0.16(0.04)$ \\
\hline 2.20 & $0.13(0.04)$ & $0.18(0.05)$ \\
\hline
\end{tabular}

its end, probably as a result of the enhanced snow metamorphism during melting and under the large temperature gradients caused by the diurnal cycle of insolation.

The optical effective radius $r_{\text {oeff }}$, defined as the effective radius corresponding to the spectral albedo obtained from surface reflectance measurements, was determined by applying DISORT iteratively for each case and wavelength. A lognormal size distribution was assumed, with the effective variance of the SSK metric in the surface layer.

For each case study, we obtained $r_{\text {oeff }}$ as a function of wavelength separately for spherical and droxtal shapes. We averaged $r_{\text {oeff }}$ in four wavebands, each $0.1 \mu \mathrm{m}$-wide, where the variation of $r_{\text {oeff }}$ was modest (intra-band standard deviations generally at most $4 \%$ ) and the signal-to-noise-ratio of the measured nadir reflectance was relatively high. The four wavebands were centred at $1.05,1.28,1.70$, and $2.20 \mu \mathrm{m}$.

In Fig. 11 the $r_{\text {oeff }}$ at the four wavebands is compared to $r_{\text {eff,sur }}$ and $r_{\text {eff, }, 5 \mathrm{~cm}}$. The striking features of Fig. 11 are (1) a good agreement of optical and measured effective radius on 23 and 26 December and on 14 January, especially for droxtal shapes, and (2) the much larger $r_{\text {oeff }}$ at the shortest SWIR wavelengths $(1.05$ and $1.28 \mu \mathrm{m})$ compared to $r_{\mathrm{SSK}}$ and to $r_{\text {oeff }}$ at the longest SWIR wavelengths $(1.70$ and $2.20 \mu \mathrm{m})$ on the other days. In all the eight case studies, the measured $r_{\mathrm{SSK} \text {,sur }}$ and $r_{\mathrm{SSK}, 5 \mathrm{~cm}}$ agreed rather well with $r_{\text {oeff }}$ at the longest SWIR wavelengths (1.70 and $2.20 \mu \mathrm{m})$, especially for droxtal shapes. Due to the smaller asymmetry parameter of droxtals, larger droxtal particles than spherical particles are needed to produce the same snow spectral albedo. Table 6 summarizes the mean $r_{\text {oeff }}\left(\overline{r_{\text {oeff }}}\right)$ for the four considered wavebands: in the case of the droxtal shape, $r_{\text {oeff }}$ at 1.05 and $1.28 \mu \mathrm{m}$ was, respectively, almost triple and double that at 1.70 and $2.20 \mu \mathrm{m}$. Comparing the $\overline{r_{\mathrm{oeff}}}$ using droxtals with the mean measured $\overline{r_{\text {eff,sur }}}(0.17 \mathrm{~mm}$, with $5 \%$ and $95 \%$ errors of -0.04 and $+0.03 \mathrm{~mm}$, respectively), we see excellent agreement at $\lambda=1.70$ and $2.20 \mu \mathrm{m}$ (with biases of -0.01 and $+0.01 \mathrm{~mm}$, respectively) but strong overestimation at $\lambda=1.05$ and $1.28 \mu \mathrm{m}$ (with biases of +0.26 and 
$+0.15 \mathrm{~mm}$, respectively), consistent with the large positive bias in the simulated albedo (Fig. 10b). Indeed, if the model overestimates the albedo for the measured particle size, it will require larger particles to obtain the observed albedo. The reason for the excessive simulated snow albedo at the shortest SWIR, and the consequent overestimated $r_{\text {oeff }}$, will be discussed in Sect. 5.3.

The errors in $r_{\text {oeff }}$ represented with bars in Fig. 11 were propagated from the errors in the modelled albedo (E05 $5_{\alpha, \bmod }$

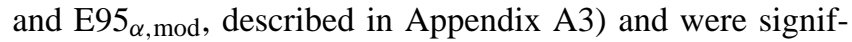
icantly larger at the shortest SWIR wavelengths (1.05 and $1.28 \mu \mathrm{m})$ than at the longest SWIR wavelengths (1.70 and $2.20 \mu \mathrm{m})$. This arises from the fact that the albedo is much less sensitive to $r_{\text {oeff }}$ at the shortest SWIR wavelengths than at the longest SWIR wavelengths.

\subsection{Sensitivity of $r_{\text {oeff }}$ to $r_{\text {snow }}$ and $v_{\text {eff }}$}

The uncertainty in snow density is not expected to have a significant impact on the modelled albedo and $r_{\text {oeff }}$ (Carmagnola et al., 2013). We tested the albedo sensitivity to $r_{\text {snow }}$ by reducing and increasing the observed values by $20 \%$. The root mean square difference from the albedo obtained using the observed $r_{\text {snow }}$ was at most $0.2 \%(0.4 \%)$ at $\lambda=1.1 \mu \mathrm{m}$ for droxtal (spherical) shapes.

We also studied the sensitivity of $r_{\text {oeff }}$ to $v_{\text {eff }}$ by comparing $r_{\text {oeff }}$ obtained using $v_{\text {eff }}$ equal to 0.1 and 0.6 , which correspond to the extreme values of $v_{\text {eff }}$ observed during the measurement period. Overall, the impact of $v_{\text {eff }}$ on $r_{\text {oeff }}$ was negligible or modest, though increasing with increasing $r_{\text {oeff }}$ and wavelength. For $\lambda<1.4 \mu \mathrm{m}$, the difference in $r_{\text {oeff }}$ between $v_{\text {eff }}=0.1$ and $v_{\text {eff }}=0.6$ was minimal (less $4 \%$ ), while in the wavebands centred at 1.7 and $2.2 \mu \mathrm{m}$ the difference reached a maximum of 13 and $18 \%$ for droxtals and spheres, respectively, thus being of the same magnitude as the uncertainty in $r_{\text {oeff }}$ associated to errors in the measurement-derived spectral albedo. These results hold only for the range of $r_{\text {oeff }}$ examined here and cannot necessarily be extended to (e.g.) cases with very large snow particles.

\section{Discussion}

\subsection{Method applied to estimate the snow particle metric}

The traditional snow particle sampling procedure adopted here involves the destruction of the 3-D matrix of the aggregated crystals and the breaking of the bonds between the crystals. Any notion on the crystal orientation is lost. Therefore, in our analyses we assume that the crystals do not have a preferred orientation, although in the case of snow surfaces exposed to persistent and directionally constant strong winds this assumption would not necessarily hold. Moreover, crystal growth driven by a strong temperature gradient is vertically oriented (Schneebeli and Sokratov, 2004). The frag- ments of ice bonds present in our samples are analyzed in the same way as the snow particles; thus their contribution to the scattered and absorbed radiation is accounted for.

The image processing protocol utilized in this study is very time consuming, but it is robust, as it is adaptable to various degrees of image sharpness and contrast, and it guarantees a reasonable degree of objectivity. Faster, more sophisticated and automatic methods to detect, classify, and measure the snow crystals from 2-D images can certainly be developed, also utilizing the expertise matured in other fields (e.g. Lindqvist et al., 2012; Rizk et al., 2014). The reliability and repeatability of the 2-D image processing procedure is closely related to the resolution of the camera's apparatus. The smallest snow particles need to include a minimum number of pixels to allow calculations of the particle metric, as the effectiveness of spatial moments has been shown to deteriorate when the object is less than about 15 pixels wide or when parts of the objects are relatively small (Coakley and van Doom, 1995). With a suitable macro objective and extension tubes, the picture resolution of present-day cameras becomes much higher than the minimum size of snow crystal fragments. However, in the present data set, the low contrast between the snow particles and the background field required a pixel averaging that reduced the image resolution, resulting in a final resolution comparable to the minimum crystal dimension. To prevent this problem, the measurement setting should provide a uniform illumination to the snow sample.

The adopted SSK metric is not affected by the extension of the crystal clusters possibly present, as it is based on the tiniest protrusion of the detected objects. The distance transformation method, applied to obtain the particle skeleton from which the SSK metric is calculated, has also previously been used to derive particle metrics from image processing (Fily et al., 1997; Gay et al., 2002; Hildebrand and Rüegsegger, 1997; Schneebeli and Sokratov, 2004). Our results (Figs. 911) show that, in several cases, the $r_{\text {eff }}$ obtained from the measured SSK metric distributions matches quite well the sphere-based $r_{\text {oeff }}$ and even better the droxtal-based $r_{\text {oeff. }}$. This supports the hypothesis that our method is suitable to measure the particle dimension that best corresponds to its scattering properties.

Computational and digital technology is continuously developing, facilitating the image processing procedure. However, sizing snow particles through image processing will always remain a time consuming technique compared to indirect optical methods (Arnaud et al., 2011; Berisford et al., 2013; Gallet et al., 2009; Painter et al., 2007). The suitability of a method should be evaluated on the basis of time limitations and availability of technical equipment, and above all depending on the research applications. 


\subsection{Impact of particle shape on albedo and $r_{\text {oeff }}$ simulations}

The albedo modelled utilizing observed $r_{\text {eff }}$, and the $r_{\text {oeff }}$ modelled on the basis of observed reflectance depend on the applied particle shape (Figs. 9-11 and Table 6). The differences between the modelling results applying spheres and droxtals are most distinct at the shortest SWIR, with the droxtal-based albedo being $\sim 10 \%$ larger than the spherebased albedo at $\lambda<1.4 \mu \mathrm{m}$ (Fig. 10), and the droxtal-based $r_{\text {oeff }}$ being on average $60 \%$ (40\%) larger than the spherebased $r_{\text {oeff }}$ at $\lambda<1.4 \mu \mathrm{m}(\lambda>1.4 \mu \mathrm{m})$ (Table 6). These results are close to those obtained by Kokhanovsky and Zege (2004) using fractal shape. The comparison between modelled and observed albedo at $\lambda>1.4 \mu \mathrm{m}$ (Figs. 9 and 10) confirmed our expectations, i.e. that the droxtal shape better represents the optical properties of the snow particles compared to spheres, when SSK is used as $r_{\text {eff }}$ in the albedo modelling. This is in agreement with previous results: over the Antarctic plateau, the particle shape assumption of aggregate of columns provided a much better agreement with measured radiances than the equivalent sphere-based assumption (Jin et al., 2008). Moreover, a large variety of observations and model calculations demonstrated that spherical particles propagate light deeper than real snow (Libois et al., 2013). In general, spherical particles can cause a large underestimation of the visible reflectance compared to more faceted and realistic particle shapes (Neshyba et al., 2003; Grenfell et al., 2005; Kokhanovsky and Zege, 2004; Picard et al., 2009; Tedesco and Kokhanovsky, 2007). Picard et al. (2009) concluded that the $r_{\text {oeff }}$ estimated from albedo measurements with an unknown particle shape has a $\pm 20 \%$ error. Indeed, an equally good fit with observed albedo can be obtained by modelling snow particles with different snow particle shapes, provided that the particle size (and its vertical profile) is a fitting parameter (Kokhanovsky and Zege, 2004; Jin et al., 2008).

Some previous studies have shown a good fit between sphere-based albedo and observations at several wavelengths, when the utilized $r_{\text {eff }}$ was the measured shortest particle dimension (Aoki et al., 2000, 2003), or the $r_{\mathrm{VA}}$ was obtained from stereological measurements (Painter and Dozier, 2004) or from SSA measurements (Carmagnola et al., 2013). We suspect that the match with observations when $r_{\mathrm{VA}}$ was applied was due to the compensation of two errors: an albedo underestimation caused by the spherical approximation, and an albedo overestimation caused by the use of $r_{\mathrm{VA}}$, which in the case of irregular and concave snow particles is smaller than $r_{\mathrm{VP}}$. However, our results also show that in some cases, under direct illumination, the spherical shape assumption may give comparable or better results than the droxtal shape assumption (Fig. 9). The reason behind this finding is discussed in detail in the next section.

\subsection{Model discrepancies}

We obtained a remarkably good match between the albedo obtained from observations and the albedo modelled applying droxtal shapes and the observed SSK metric at $\lambda>$ $1.4 \mu \mathrm{m}$. On the contrary, at $\lambda<1.4 \mu \mathrm{m}$ snow albedo was largely overestimated in most cases, in particular using droxtals. Consequently, at $\lambda<1.4 \mu \mathrm{m}$ the $r_{\text {oeff }}$ calculated from the observation-derived albedo was much larger than at longer wavelengths. In only one case (on 14 January) albedo was underestimated at all wavelengths, most probably because the fresh snow still present at the time of the nadir-reflectance measurements had already undergone a strong metamorphism $1.5 \mathrm{~h}$ later, when the snow particles were photographed (see Table 1), due to the intense melting that took place on that day (Fig. 2).

The discrepancy between modelled and observed albedo at some wavebands when at the same time a good match is obtained at other wavebands has been frequently reported (Aoki et al., 2000, 2007; Carmagnola et al., 2013; Dominé et al., 2006; Fily et al., 1997; Grenfell et al., 1994; Kuchiki et al., 2009). Equivalently, this translates into a change of $r_{\text {oeff }}$ with changing wavelengths.

The use of $r_{\mathrm{VA}}$ (or SSA) as $r_{\mathrm{eff}}$ has often resulted in a rather good simulation (or slight overestimation) of the visible albedo, and in a significant underestimation of the albedo at $\lambda>1.4 \mu \mathrm{m}$ (Grenfell et al., 1994; Painter and Dozier, 2004; Carmagnola et al., 2013). When half the shortest particle dimension was used as $r_{\text {eff }}$, a similar result was obtained in some cases (Aoki et al., 2007; Kuchiki et al., 2009), while in another case a good match between modelled and observed albedo was achieved at $\lambda>1.4 \mu \mathrm{m}$, while albedo was overestimated at $1.0<\lambda<1.4 \mu \mathrm{m}$ (Aoki et al., 2000). This last case is in agreement with our findings (Fig. 10), and in line with Kokhanovsky et al. (2011), who retrieved $r_{\text {oeff }}$ much larger at $\lambda=0.865 \mu \mathrm{m}$ than at $\lambda=1.24 \mu \mathrm{m}$. In all these studies, the bias between simulated and observed albedo was more or less positive at $\lambda<1.4 \mu \mathrm{m}$ and more or less negative at $\lambda>1.4 \mu \mathrm{m}$. Similarly, the reported $r_{\text {oeff }}$ calculated from reflectance measurements were much smaller at $\lambda>1.4 \mu \mathrm{m}$ than at $\lambda<1.4 \mu \mathrm{m}$ (Aoki et al., 2007; Fily et al., 1997; Kuchiki et al., 2009).

Traditionally, these results are explained with the particle size differences in the vertical profile of the snowpack: the albedo at shorter wavelengths conveys snow particle size information from deeper layers than the albedo at longer wavelengths. At $\lambda>1.4 \mu \mathrm{m}$ the penetration depth of light is only a few millimetres (Fig. 8), and often this thin, uppermost snow layer is characterized by smaller particles than the deeper layers (Aoki et al., 2000; Carmagnola et al., 2013). An ad hoc vertical profile of snow particle size in the uppermost few millimetres of the snowpack has sometimes been utilized to conciliate modelled and observed albedo (Grenfell et al., 1994). However, when applying a detailed vertical profile of particle size in the albedo calculations, the discrepancies with 
observations were not solved (Aoki et al., 2000, 2007; Carmagnola et al., 2013). Moreover, in our case, snow particles were larger at the surface than at deeper layers (Fig. 11), as a result of the intense snow metamorphism occurring around midday with direct insolation, positive sensible heat flux, and temperature close to the melt point.

Some other hypotheses have been formulated to explain the underestimation of the modelled albedo at $\lambda>1.4 \mu \mathrm{m}$ : Carmagnola et al. (2013) attributed it to the uncertainty on the value of the ice refractive index, whereas Aoki et al. (2007) to the fine structure of the thin sun crust present at the surface. This last hypothesis, however, was not confirmed by later observations, when wet, melting snow without sun crust still gave rise to the same discrepancy (Kuchiki et al., 2009). Kuchiki et al. (2009) explained the underestimation of the satellite retrieved $r_{\text {oeff }}$ compared to observations in relation to the microstructure of the snow surface. They hypothesized that the small irregularities and protrusions present on the surface of large particles had a dominant contribution to the reflected light at the longest SWIR.

On the basis of our results, we cannot exclude the possibility that uncertainties in ice refractive index may contribute to the wavelength dependence of $r_{\text {oeff. }}$. If this were the main reason for the wavelength dependence, we would expect that the relative difference in $r_{\text {oeff }}$ between different wavelengths is similar from case to case. Indeed, we note from Fig. 11 that the best estimate of $r_{\text {oeff }}$ at $\lambda=2.20 \mu \mathrm{m}$ is consistently slightly larger than that at $\lambda=1.70 \mu \mathrm{m}$ (in relative terms, by 13-20\% depending on case). However, the difference in $r_{\text {oeff }}$ between the weakly absorbing wavelengths $(\lambda 1.05=\mu \mathrm{m}$ and $\lambda=1.28 \mu \mathrm{m})$ and $\lambda=1.70 \mu \mathrm{m}$ depends strongly on the case: the relative difference between 1.05 and $1.70 \mu \mathrm{m}$ varies from 45 to $391 \%$, and that between $\lambda=1.28 \mu \mathrm{m}$ and $\lambda=1.70 \mu \mathrm{m}$ from 53 to $158 \%$. This strong case dependency suggests that uncertainties in refractive index are probably not the primary contributing factor to the wavelength dependence of $r_{\text {oeff }}$. Instead, the explanation given by Kuchiki et al. (2009) better suits our findings. Indeed, their surface conditions strongly resemble our observations. We obtained an almost wavelength independent $r_{\text {oeff }}$ when the surface was rather smooth and homogeneous because of fresh snow (on 23 December and 14 January) and drifted snow (on 26 December). The difference in optical effective particle radius between different wavelengths was largest on 5 and 6 January, when strong melting occurred and large, irregular surface snow particles with thin protrusions coexisted with smaller particles (see Table 3), causing a rough texture in the millimetre scale. This seems to be a rather common feature of the Antarctic snow surface, also observed on the high plateau (Gallet et al., 2014). At the shortest SWIR wavelengths, photons can penetrate several millimetres into the snowpack (see Fig. 7), and their absorption/scattering takes place with higher probability in the biggest snow particles, where the optical path is longest. Thus, the relative contribution of the biggest particles to the reflected irradiance is larger than the contribution of their thin branches. On the other hand, at the longest SWIR wavelengths photons have very short optical path in the snow (the penetration depth is smaller than $1 \mathrm{~mm}$ ), and therefore, they have low chances to penetrate beyond the tiniest protruding branches, which then contribute to the reflected irradiance in much larger proportion than at the shortest SWIR wavelengths. This may explain why we obtained consistent agreement between $r_{\text {eff }}$ and $r_{\text {oeff }}$ at the longest SWIR wavelengths in all case studies, when assuming droxtal-shaped snow particles.

We clearly observed a relationship between the modelling biases at the shortest SWIR and the mm-scale surface roughness. Roughness increased during snowmelt as compared to immediately after snowfall, as previously observed (Anttila et al., 2014; Fassnacht et al., 2009). The cavities developed during the melting trap a fraction of the reflected light into their walls, particularly at the shortest wavelengths due to multiple reflections between the walls. Thus, at those shortest wavelengths the albedo is lower for a rough surface (in the millimetre scale) than for a flat surface, and $r_{\text {oeff }}$ is larger than $r_{\text {eff. }}$ The modelling biases may have also been affected by the larger (cm-scale) surface roughness such as sastrugi, and their orientation with respect to the solar position. Indeed, the presence of sastrugi causes an albedo reduction with respect to a flat snow surface (Kuhn, 1974), and this effect depends on the albedo itself, being stronger for intermediate values of albedo (i.e. in the near-infrared spectral range, Warren et al., 1998). On 26 December, when $r_{\text {oeff }}$ was almost identical for all wavelengths, surface striations were small, and the solar zenith angle at the time of the spectral reflectance measurements was smaller than in the following days. On 5 and 6 January, when $r_{\text {oeff }}$ for the shortest SWIR was largest, the snow metamorphism due to the melting was very strong and caused a deepening of the sastrugi. Later, the melting continued, but the occasional snowfall events reduced the surface roughness at the $\mathrm{cm}$-scale.

Following this interpretation, when the droxtal shape is applied, the SSK metric seems to rather well represent the scattering properties of the snow at $\lambda>1.0 \mu \mathrm{m}$ when the surface is smooth and the snow particle population is homogeneous in size, but it overestimates $r_{\text {oeff }}$ for $1.0<\lambda<1.4 \mu \mathrm{m}$ when there is a 10-20 times size difference among the coexisting snow particles and branches, and the millimetre- and centimetre-scale surface roughness is significant. These findings strongly suggest that a single particle metric distribution is not sufficient to describe the scattering properties of surfaces composed of mixed-size particles. This may have profound implications in the interpretations of satellite-based reflectance measurements, presently based on single size distributions and on models that neglect the surface roughness (Painter et al., 2003; Lyapustin et al., 2009). Thus, our results highlight a relevant observational and modelling gap. Until now, studies on the impact of surface roughness on snow albedo have focused mainly on the effect of sastrugi (Leroux and Fily, 1998; Warren et al., 1998; Hudson and Warren, 
2007; Lyapustin et al., 2010; Zhuravleva and Kokhanovsky, 2011). Warren (1982) indicates that surface roughness features reduce the albedo when their dimension is comparable to or larger than the penetration depth of light. This implies that surface roughness of amplitude $10 \mathrm{~cm}$ (such as sastrugi) reduces the visible albedo, but much smaller irregularities can affect the near-infrared albedo. Nevertheless, only few measurements of millimetre-scale snow surface roughness have been carried out so far (Anttila et al., 2014; Frassnacht et al., 2009; Manninen, 1997), and they have not yet been applied to interpret the surface albedo.

\section{Conclusions}

This study illustrates a method to extract a snow particle size metric, the SSK (shortest skeleton branch), from 2-D snow macro photos. From the metric distributions, we calculated the effective particle size $r_{\text {eff }}$, which was then used to model the surface albedo. The SSK metric provided albedo values that agreed well with the observed albedo values for $\lambda>1.4 \mu \mathrm{m}$, especially when the snow particles were modelled with droxtal shapes (Fig. 9). For $\lambda<1.4 \mu \mathrm{m}$, a good fit between the modelled and the observed albedo was still present in some cases, but, on average, a large positive bias was observed (Fig. 10).

The measured $r_{\text {eff }}$ were then compared to the optical effective radius $r_{\text {oeff }}$ calculated from the surface spectral albedo, assuming that snow is optically equivalent to a collection of spheres or droxtals, which have the same $r_{\mathrm{VP}}$ as the snow particles. Considering the cases when the surface was rather smooth and homogeneous because of fresh snow (on 23 December and 14 January) and drifted snow (on 26 December), we found that $r_{\text {eff }}$ corresponded to $r_{\text {oeff }}$ remarkably well at all wavelengths, particularly for droxtal shape calculations (Fig. 11). We explain this finding by arguing that the $r_{\text {eff }}$ based on the SSK metric is a close approximation of the $r_{\mathrm{VP}}$ of the snow particles. In the other cases, the optical effective radius $r_{\text {oeff }}$ depended on wavelength, confirming previous studies (Aoki et al., 2000, 2007; Carmagnola et al., 2013; Dominé et al., 2006; Fily et al., 1997; Grenfell et al., 1994; Kuchiki et al., 2009), and $r_{\text {eff }}$ corresponded to $r_{\text {oeff }}$ only at the longest SWIR wavelengths. Our observations revealed that the wavelength dependence of $r_{\text {oeff }}$ varied with the seasonal evolution of the snow surface layer. We interpreted these findings on the basis of the observed shape and size distributions of the snow particles at the surface, and based on the evolution of the millimetre- and centimetre-scale surface roughness features. We suggest that when large, irregular particles such as surface hoar and faceted polycrystals were present at the surface, the contribution of the largest particles to the reflected irradiance dominated at the shortest SWIR wavelengths, while the contribution of the thinnest protrusions of the irregular crystals dominated at the longest SWIR wavelengths. This type of particle population was de- veloped during the alternation of nocturnal freezing and diurnal melting, and was associated with mm-scale surface cavities, which possibly contribute to the reduction of the albedo at the shortest SWIR wavelengths. These results indicate that more than just one particle metric distribution is needed to characterize the snow scattering properties at all optical wavelengths, and underline the limitation of the plane parallel assumption made in many snow radiative transfer models (Lyapustin et al., 2009; Painter et al., 2003).

Considering all uncertainties in the observations, in the methods of analysis, and in the modelling assumptions, the very good agreement between $r_{\text {oeff }}$ and $r_{\text {eff }}$ and between modelled and observed albedo in the cases of smooth and homogeneous surfaces is encouraging. It suggests that the method applied to measure snow particle size is adequate for optical applications, that the SSK metric offers a good synthesis of the particle's physical dimension relevant for light scattering, and that the droxtal shape represents the scattering properties of the snow particles better than the spherical shape. In the cases of rougher surfaces with heterogeneous particle population, the SSK metric characterizes the scattering by snow only for $\lambda>1.4 \mu \mathrm{m}$. For shorter wavelengths, a larger metric should be applied, and this will be investigated in our future studies.

The analyzed wavelength range $(1.0-2.5 \mu \mathrm{m})$ is critical from the point of view of the surface radiation budget, as it included $80 \%$ (66\%) of the net shortwave radiation absorbed by the snow during the clear-sky (overcast) cases examined. In the overcast cases, all characterized by fresh snow at the surface, the negligible bias of the droxtal-based modelled albedo in the 1.0-2.5 $\mu \mathrm{m}$ range resulted in a negligible bias in the absorbed shortwave radiation. In the clear-sky cases, the positive bias of the droxtal-based modelled albedo caused an average underestimation of the absorbed shortwave radiation of about $-15 \mathrm{~W} \mathrm{~m}^{-2}$.

The impact of millimetre-scale snow surface roughness on the surface albedo needs to be better understood. A field campaign addressing the characterization of snow roughness texture with the dimension ranging from centimetres to millimetres is being planned, with the goal of measuring the roughness both in the limited field of view of ground-based spectral albedo sensors and in the large footprint area of remote sensing sensors. 


\section{Appendix A: Calculation of errors in albedo, $r_{\text {eff }}$, and \\ $v_{\text {eff }}$}

Throughout this paper, uncertainty in albedo, $r_{\text {eff }}$, and $v_{\text {eff }}$ is estimated in terms of the "5 and $95 \%$ errors" (E05 and E95, respectively). The $5 \%(95 \%)$ error is defined as the difference between the lower (upper) limit of the $90 \%$ confidence interval and the best estimate.

\section{A1 Errors in the albedo derived from reflectance measurements}

We briefly summarize here the independent errors in the measurement-derived albedo:

1. error in repeatability of the snow reflectance $\sigma_{\mathrm{rpt}}$, equal to the normalized standard deviation of reflectance among 30 consecutive spectra;

2. error in horizontal levelling of the reference Spectralon $\sigma_{\text {ref }}$, equal to the normalized standard deviation of Spectralon reflectance among 30 consecutive spectra;

3. bias due to the tilting of the snow surface, positive in the downhill direction $\left(\Delta_{\text {tilt,down }}\right)$ and negative in the uphill direction $\left(\Delta_{\text {tilt,up }}\right)$;

4. 5 and $95 \%$ errors of $\Phi\left(\mathrm{E} 05_{\Phi}\right.$ and $\mathrm{E} 95_{\Phi}$, respectively), which propagate to the hemispherical albedo when applying Eq. (B4) (see Appendix B).

The resulting 5 and $95 \%$ errors in the measurement-derived albedo ( $E 05_{\alpha, \mathrm{obs}}$ and $E 95_{\alpha, \mathrm{obs}}$, respectively) are the following:

$$
\begin{aligned}
& \mathrm{E} 95_{\alpha, \mathrm{obs}}=\sqrt{c^{2} \cdot\left(\sigma_{\mathrm{rpt}}^{2}+\sigma_{\mathrm{ref}}^{2}\right)+\Delta_{\text {tilt,down }}^{2}+\mathrm{E} 95_{\Phi}^{2}} \\
& \mathrm{E} 05_{\alpha, \mathrm{obs}}=-\sqrt{c^{2} \cdot\left(\sigma_{\mathrm{rpt}}^{2}+\sigma_{\mathrm{ref}}^{2}\right)+\Delta_{\text {tilt,up }}^{2}+\mathrm{E}^{2} 5_{\Phi}^{2}},
\end{aligned}
$$

where $c=1.6456$ is the factor that gives the 5 and $95 \%$ confidence limits of the two normally distributed errors $\sigma_{\text {rpt }}$ and $\sigma_{\text {ref }}$.

\section{A2 Errors in $r_{\text {eff }}$ and $v_{\text {eff }}$}

The independent errors in the particle metric distributions (described in Sect. 3.1.4) that propagate to the calculation of $r_{\text {eff }}$ and $v_{\text {eff }}$ are the following:
1. 5 and $95 \%$ subjectivity errors of the SSK metric distributions (E05 sub and E95 sub, respectively) - They are calculated as the averaged root-mean-square error between the SSK metric obtained by one experienced and two unexperienced persons in image processing, divided by the square root of the number of cases, and multiplied by the coefficient $c=1.6456$.

2. 5 and $95 \%$ representativeness errors of the SSK metric distributions $\left(\mathrm{E} 05_{\mathrm{rpr}}\right.$ and $\mathrm{E} 95_{\mathrm{rpr}}$, respectively) - Depending on whether the error in $r_{\text {eff }}$ or $v_{\text {eff }}$ was considered, the bootstrap realizations were arranged according to their $r_{\text {eff }}$ or $v_{\text {eff. }}$.

The resulting 5 and $95 \%$ errors in $r_{\text {eff }}$ and $v_{\text {eff }}\left(\mathrm{E} 05_{r_{\text {eff }}, v_{\text {eff }}}\right.$ and $\mathrm{E} 95_{r_{\text {eff }}, v_{\text {eff }}}$, respectively) are the following:

$$
\begin{aligned}
& \mathrm{E} 95_{r_{\mathrm{eff}}, v_{\mathrm{eff}}}=\sqrt{\mathrm{E} 95_{\mathrm{sub}}^{2}+\mathrm{E} 95_{\mathrm{rpr}}^{2}} \\
& \mathrm{E} 05_{r_{\mathrm{eff}}, v_{\mathrm{eff}}}=-\sqrt{\mathrm{E} 05_{\mathrm{sub}}^{2}+\mathrm{E} 05_{\mathrm{rpr}}^{2}} .
\end{aligned}
$$

When averaging over several cases, the error of the mean $r_{\text {eff }}\left(v_{\text {eff }}\right)$ is obtained from the mean of the errors of all the cases divided by the square root of the number of cases (see Table 5).

\section{A3 Errors in the difference between model- and measurement-derived albedo}

The errors expressed by Eqs. (A3) and (A4) propagate to the model-derived albedo. As the smallest particles of the confidence interval generate the highest albedo, the $5 \%$ error of $r_{\text {eff }}\left(\mathrm{E} 05_{r_{\text {eff }}, v_{\text {eff }}}\right)$ corresponds to the $95 \%$ error of the model-derived albedo (E95 $\alpha$,mod). Conversely, the largest particles generate the smallest albedo; therefore E95 $r_{\text {eff }}, v_{\text {eff }}$ is proportional to the $5 \%$ error of the modelderived albedo (E05 $\left.5_{\alpha \text {,mod }}\right)$. The 5 and $95 \%$ errors of the bias between model- and measurement-derived albedo (E05 $\Delta \alpha$ and $\mathrm{E} 95_{\Delta \alpha}$, respectively) are calculated as follows:

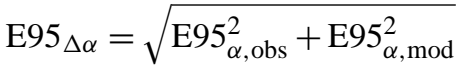

$$
\begin{aligned}
& \mathrm{E} 05_{\Delta \alpha}=-\sqrt{{\mathrm{E} 05_{\alpha, \mathrm{obs}}^{2}+\mathrm{E} 05_{\alpha, \bmod }^{2}}^{2}}
\end{aligned}
$$

When averaging over several cases, the errors of the mean bias are obtained from the mean of the errors of all the cases divided by the square root of the number of cases (see Fig. 10). 
Table A1. List of acronyms and symbols.

\begin{tabular}{|c|c|}
\hline ASD & FieldSpec JR spectroradiometer, manufactured by Analytical Spectral Devices Inc., now PANalytical \\
\hline BRDF & Bidirectional reflectance distribution function \\
\hline DISORT & Discrete Ordinates Radiative Transfer Program for a Multi-Layered Plane-Parallel Medium \\
\hline $\mathrm{E} 05_{r_{\mathrm{eff}}, v_{\mathrm{eff}}}=5 \%$ & $\begin{array}{l}\text { Error of the effective radius/variance, i.e. the difference between the lower limit } \\
\text { of the } 90 \% \text { confidence interval and the best estimate }\end{array}$ \\
\hline E05 rpr & $5 \%$ representativeness error of the SSK metric \\
\hline E05 sub & $5 \%$ subjectivity error of the SSK metric \\
\hline $\mathrm{E} 05_{\Delta \alpha}$ & $5 \%$ error of the bias between model- and measurement-derived albedo \\
\hline${\mathrm{E} 05_{\Phi}^{2}}^{2}$ & $5 \%$ error of the parameterized $\Phi$ \\
\hline $\mathrm{E} 05_{\alpha, \bmod }$ & $5 \%$ error of the modeled albedo applying the SSK metric \\
\hline $\mathrm{E} 05_{\alpha, \mathrm{obs}}$ & $5 \%$ error of the albedo derived from nadir reflectance measurements \\
\hline $\mathrm{E} 95_{r_{\mathrm{eff}}, v_{\mathrm{eff}}}$ & $\begin{array}{l}95 \% \text { error of the effective radius/variance, i.e. the difference between the upper } \\
\text { limit of the } 90 \% \text { confidence interval and the best estimate }\end{array}$ \\
\hline E95 rpr & $95 \%$ representativeness error of the SSK metric \\
\hline $\mathrm{E} 95_{\text {sub }}$ & $95 \%$ subjectivity error of the SSK metric \\
\hline $\mathrm{E} 95_{\Delta \alpha}$ & $95 \%$ error of the bias between model- and measurement-derived albedo \\
\hline $\mathrm{E} 95_{\Phi}^{2}$ & $95 \%$ error of the parameterized $\Phi$ \\
\hline $\mathrm{E} 95_{\alpha, \bmod }$ & $95 \%$ error of the modeled albedo applying the SSK metric \\
\hline $\begin{array}{l}\mathrm{E} 95_{\alpha, \mathrm{obs}} \\
\mathrm{FOV}\end{array}$ & $\begin{array}{l}95 \% \text { error of the albedo derived from nadir reflectance measurements } \\
\text { field of view }\end{array}$ \\
\hline$F_{0}$ & incident irradiance at the solar zenith angle $\theta_{0}\left(\mathrm{~W} \mathrm{~m}^{-2} \mu \mathrm{m}^{-1}\right)$ \\
\hline$I_{\mathrm{n}}$ & radiance reflected into the nadir direction \\
\hline$I_{\mathrm{r}}$ & radiance reflected into a particular direction $\left(\mathrm{W} \mathrm{m}^{-2} \mathrm{sr}^{-1} \mu \mathrm{m}^{-1}\right)$ \\
\hline$L_{i}$ & dimension of the $i$ th particle \\
\hline NIR & near-infrared light $(0.7-1.0 \mu \mathrm{m})$ \\
\hline$Q_{\text {ext }}$ & extinction efficiency \\
\hline SR & severely roughened \\
\hline SSA & specific surface area of the snow particle population \\
\hline SSPs & single-scattering properties \\
\hline SWIR & shortwave infrared light $(1.0-2.5 \mu \mathrm{m})$ \\
\hline SWIR1 & shortwave infrared light $(1.0-1.83 \mu \mathrm{m})$ : spectral region of the second ASD sensor \\
\hline SWIR2 & shortwave infrared light $(1.83-2.5 \mu \mathrm{m})$ : spectral region of the third ASD sensor \\
\hline Swn & broadband net shortwave radiation $(0.35-2.5 \mu \mathrm{m})$ absorbed by the snow surface \\
\hline$\overline{\operatorname{Swn}_{\Delta \lambda}}$ & mean net shortwave radiation integrated over a distinct waveband \\
\hline$T_{\text {snow }}$ & snow temperature \\
\hline VIS & visible light $(0.4-0.7 \mu \mathrm{m})$ \\
\hline VNIR & visible and near-infrared $(0.35-1.0 \mu \mathrm{m})$ : spectral region of the first ASD sensor \\
\hline bw & black and white \\
\hline$g$ & asymmetry parameter \\
\hline$m_{2}, m_{3}, m_{4}$ & second, third, and fourth moment of the measured metric distribution \\
\hline$r_{i}$ & geometrical radius of the scattering particle \\
\hline$r_{\text {eff }}$ & effective radius of the measured metric distribution \\
\hline$r_{\text {oeff }}$ & optically equivalent effective radius \\
\hline$r_{\lambda}$ & $\begin{array}{l}\text { mean optically equivalent effective radius in the } 0.1 \mu \mathrm{m} \text {-wide waveband } \\
\text { centered on the wavelength } \lambda\end{array}$ \\
\hline$v_{\text {eff }}$ & effective variance of the measured metric distribution \\
\hline$r_{\mathrm{VA}}$ & volume-to-surface area equivalent radius of the measured metric distribution \\
\hline$r_{\mathrm{VP}}$ & volume-to-projected area equivalent radius of the measured metric distribution \\
\hline$\Delta_{\text {tilt,down }}$ & $\begin{array}{l}\text { positive bias in reflectance/albedo due to the tilting of the snow surface in } \\
\text { the downhill direction }\end{array}$ \\
\hline$\Delta_{\text {tilt,up }}$ & $\begin{array}{l}\text { negative bias in reflectance/albedo due to the tilting of the snow surface in } \\
\text { the uphill direction }\end{array}$ \\
\hline$\Delta z$ & geometrical thickness of a snow layer \\
\hline$\Phi$ & anisotropic reflectance factor \\
\hline$\Phi_{\mathrm{n}}$ & anisotropic reflectance factor in the nadir direction \\
\hline$\alpha$ & hemispherical spectral albedo \\
\hline$\alpha_{\mathrm{b}}$ & broadband albedo \\
\hline$\overline{\alpha_{\mathrm{b}, \Delta \lambda}}$ & mean surface albedo integrated over a distinct waveband \\
\hline$\theta_{0}$ & solar zenith angle \\
\hline$\theta_{0, \text { eff }}$ & effective solar zenith angle \\
\hline$\theta_{\mathrm{V}}$ & viewing zenith angle \\
\hline$\lambda$ & wavelength \\
\hline$\rho_{\text {snow }}$ & snow density \\
\hline$\rho_{\text {ice }}$ & ice density \\
\hline$\sigma_{\text {ref }}$ & error in horizontal levelling of the reference Spectralon \\
\hline$\sigma_{\mathrm{rpt}}$ & error in repeatability of the snow reflectance \\
\hline$\tau$ & optical thickness of a snow layer \\
\hline$\phi$ & relative azimuth angle \\
\hline$\omega$ & single-scattering albedo \\
\hline 2-D & two-dimensional \\
\hline
\end{tabular}




\section{Appendix B: Calculation of hemispherical albedo using nadir reflectance and anisotropic reflectance factor measured by Hudson et al. (2006)}

The measured snow nadir reflectance $\left(I_{\mathrm{n}}\right)$ was integrated over a FOV of $25^{\circ}$, and therefore it is expressed as follows:

$I_{\mathrm{n}}\left(\theta_{0}\right)=\frac{\int_{0}^{360 \circ} \int_{0}^{12.5 \circ} I_{\mathrm{r}}\left(\theta_{0}, \theta_{\mathrm{v}}, \phi\right) \cos \theta_{\mathrm{v}} \sin \theta_{\mathrm{v}} \mathrm{d} \theta_{\mathrm{v}} \mathrm{d} \phi}{F_{0}}$,

where $I_{\mathrm{r}}$ is the radiance reflected into a particular direction $\left(\mathrm{W} \mathrm{m}^{-2} \mathrm{sr}^{-1} \mu \mathrm{m}^{-1}\right), \theta_{\mathrm{v}}$ is the viewing zenith angle, $\phi$ is the relative azimuth angle, and $F_{0}$ is the incident irradiance at that particular $\theta_{0}\left(\mathrm{~W} \mathrm{~m}^{-2} \mu \mathrm{m}^{-1}\right)$. Our objective is to obtain $\alpha$, which reads as follows:

$\alpha\left(\theta_{0}\right)=\frac{\int_{0}^{360 \circ} \int_{0}^{90 \circ} I_{\mathrm{r}}\left(\theta_{0}, \theta_{\mathrm{v}}, \phi\right) \cos \theta_{\mathrm{v}} \sin \theta_{\mathrm{v}} \mathrm{d} \theta_{\mathrm{v}} \mathrm{d} \phi}{F_{0}}$.

Due to the anisotropic scattering by the snow particles, the diffuse radiation reflected by the snow surface is not isotropic, but it is distributed according to the bidirectional reflectance distribution function (BRDF). In principle, knowing the snow BRDF it is possible to convert the radiances measured at a specific viewing angle to spectral albedo. Hudson et al. (2006) calculated the snow BRDF at Dome Concordia, over the Antarctic Plateau, in the form of anisotropic reflectance factor $(\Phi)$, defined as $\pi$ times the ratio of radiance reflected into a particular direction, to the following reflected flux:

$$
\Phi\left(\theta_{0}, \theta_{\mathrm{v}}, \phi\right)=\frac{\pi I_{\mathrm{r}}\left(\theta_{0}, \theta_{\mathrm{v}}, \phi\right)}{\int_{0}^{360 \circ} \int_{0}^{90 \circ} I_{\mathrm{r}}\left(\theta_{0}, \theta_{\mathrm{v}}, \phi\right) \cos \theta_{\mathrm{v}} \sin \theta_{\mathrm{v}} \mathrm{d} \theta_{\mathrm{v}} \mathrm{d} \phi} .
$$

By integrating $\Phi$ in the $25^{\circ} \mathrm{FOV}$ of the ASD spectroradiome$\operatorname{ter}\left(\Phi_{\mathrm{n}}\right)$ and combining Eqs. (B1)-(B3) we get the following:

$\alpha\left(\theta_{0}\right)=\frac{I_{\mathrm{n}}\left(\theta_{0}\right)}{\Phi_{\mathrm{n}}\left(\theta_{0}\right)}$.

We parameterized $\Phi_{\mathrm{n}}$ based on the measurements of Hudson et al. (2006), who derived $\Phi$ from their observations of snow reflectance at various viewing zenith angles and relative azimuth angles, done using an ASD with a $15^{\circ}$ FOV. Dome Concordia is characterized by very fine snow particles, which maximize the snow reflectance, and by small and randomly distributed sastrugi, which affect $\Phi$ especially at the large viewing zenith angles, and reduce the anisotropy of $\Phi$ compared to that of sunlight reflected from a flat snow surface (Hudson and Warren, 2007). We estimate that the surface roughness features at Aboa are quite similar to the ones present at Dome Concordia. In any case, the results by Hudson et al. (2006) have also been confirmed by measurements carried out in the Arctic (Lyapustin et al., 2010). We utilized the subset of Hudson et al.'s (2006) $\Phi$ data at $\theta_{\mathrm{v}}=7.5^{\circ}$ (available online as auxiliary Table jgrd13053-sup-0003-ts02.txt) to derive a specific parameterization of $\Phi_{\mathrm{n}}$ as a function of their measured $I_{\mathrm{n}}$ (auxiliary Table jgrd13053-sup-0002-ts01.txt) and $\cos \theta_{0}$ using the following multi-linear regression model:

$\ln \Phi_{\mathrm{n}}=a+b \cdot \ln I_{\mathrm{n}}+c \cdot \cos \left(\theta_{0}\right),\left\{\begin{array}{l}a=-0.25 \pm 0.03 \\ b=0.173 \pm 0.002 \\ c=0.40 \pm 0.05\end{array}\right.$.

The $I_{\mathrm{n}}$ was measured applying a similar procedure as that used in this study, with the input fiber optic of the ASD receiving light reflected from a Spectralon plate in a $15^{\circ} \mathrm{FOV}$. The regression coefficients $a, b$, and $c$ were determined with the least squares method and are given in Eq. (B5) with the $90 \%$ confidence intervals. The square of the linear correlation coefficient is 0.938 . Figure B1 illustrates the data utilized for the derivation of Eq. (B5) (black dots) and the fitted multi-linear model (red dots): it shows that $\Phi_{\mathrm{n}}$ is smaller than 1 and it increases with increasing $I_{\mathrm{n}}$. Indeed, Hudson et al. (2006) observed that snow is brightest $(\Phi>1)$ when viewed near the horizon and darkest $(\Phi<1)$ when viewed near nadir, and this anisotropy decreases with increasing $I_{\mathrm{n}}$.

Particle size variations and changes in the orientations and dimensions of the surface roughness features during the progress of the season represent sources of uncertainty for the $\Phi$ parameterization. Indeed, an increase in particle size increases the anisotropy of the BRDF pattern, strengthening the forward reflectance peak of snow. Because of the short path length of SWIR light into the snow compared to the visible wavelengths, uncertainties are particularly significant in this waveband region. Sastrugi orientation did not change during our measurement period, but their dimension increased, possibly causing a decreased BRDF anisotropy. A further source of uncertainty is that the data for $\theta_{\mathrm{v}}=7.5^{\circ}$ in Hudson et al. (2006) do not represent exactly the range of viewing angles needed for $\Phi_{\mathrm{n}}$ (i.e. $\theta_{\mathrm{v}}=0-12.5^{\circ}$ ). First, $\theta_{\mathrm{v}}=7.5^{\circ}$ corresponds formally to $\theta_{\mathrm{v}}=0-15^{\circ}$, and more importantly, Hudson et al. (2006) did not actually measure radiances at $\theta_{\mathrm{v}}=7.5^{\circ}$ but rather used median values for $\theta_{\mathrm{v}}=22.5^{\circ}$, which represents the range $\theta_{\mathrm{v}}=15-30^{\circ}$. Without a better method to quantify these uncertainties on $\Phi_{\mathrm{n}}$, we estimated the confidence intervals for $\Phi_{\mathrm{n}}$ utilizing the $90 \%$ confidence intervals of the regression coefficients in Eq. (B5) (E05 $\Phi$ and $\mathrm{E} 95_{\Phi}$, respectively). We then utilized Eq. (B4) to calculate the spectral albedo.

Hudson et al. (2006) assumed that their measured $I_{\mathrm{n}}$ in overcast conditions is equivalent to the diffuse $\alpha$. However, in fact, even in a case with isotropic incident radiation, $I_{\mathrm{n}}$ tends to be smaller than $\alpha$, especially at strongly absorbing wavelengths (i.e. low $\alpha$ ) where first-order scattering makes a large contribution to the reflected radiance. The fundamental reason for this is the anisotropic scattering by snow particles. Reflectance towards the zenith requires scattering in the backward hemisphere $\left(90-180^{\circ}\right)$, but forward scattering dominates in the case of snow particles. Therefore, we applied Eqs. (B4) and (B5) to all our cases, using an effective 


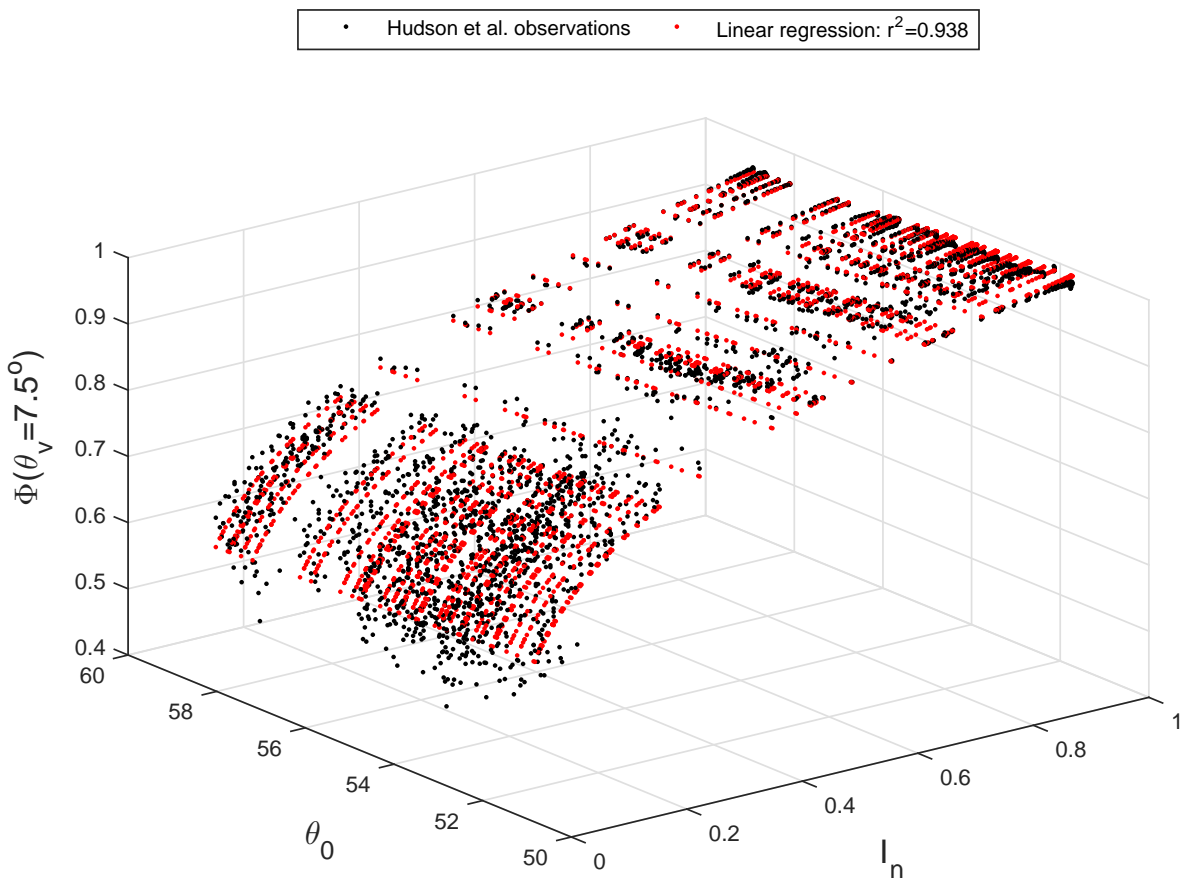

Figure B1. Anisotropic reflectance factor $(\Phi)$ for viewing zenith angle $\theta_{\mathrm{V}}$ equal to $7.5^{\circ}$ calculated from snow reflectance measurements at Dome Concordia (Antarctic Plateau) by Hudson et al. (2006) vs. solar zenith angle $\theta_{0}$ and nadir reflectance $I_{\mathrm{n}}$ (black dots). The red dots correspond to the multi-linear regression of the logarithm of $\Phi$ as a function of the logarithm of spectral albedo and the cosine of $\theta_{0}$ (see Eq. B5).

solar zenith angle $\left(\theta_{0, \text { eff }}\right)$ of $55^{\circ}$ for the $I_{\mathrm{n}}$ measured in overcast conditions. This is somewhat of an ad hoc choice, based on the notion that in two-stream approximations in which the angular distribution of diffuse radiation is not represented explicitly, it is typically approximated with a diffusivity factor of $D=1.5-2$ (Edwards and Slingo, 1996), corresponding to $\theta_{0, \text { eff }}=\cos ^{-1}(1 / D)=48.2-60^{\circ}$. Varying $\theta_{0, \text { eff }}$ in this range in Eq. (B5) would change the resulting snow albedo at most by $3-4 \%$ compared to the results for $\theta_{0, \text { eff }}=55^{\circ}$. 
Acknowledgements. The study was supported by the Academy of Finland through the AMICO and A4 projects (contracts 263918 and 254195, respectively) and by the Nordic Centre of Excellence project SVALI, "Stability and Variations of Arctic Land Ice", funded by the Nordic Top-level Research Initiative (TRI). This publication is SVALI contribution number 65.We thank the FINNARP logistics team and Antti Aarva for technical support, as well as the editor F. Dominé, reviewer T. Aoki, and another anonymous reviewer for their constructive comments.

Edited by: F. Dominé

\section{References}

Anttila, K., Manninen, T., Karjalainen, T., Lahtinen, P., Riihelä, A., and Siljamo, N.: The temporal and spatial variability in submeter scale surface roughness of seasonal snow in Sodankylä Finnish Lapland in 2009-2010, J. Geophys. Res.-Atmos., 119, 92369252, doi:10.1002/2014JD021597, 2014.

Aoki, T., Aoki, T., Fukabori, M., Tachibana, Y., Zaizen, Y., Nishio, F., and Oishi, T.: Spectral albedo observation on the snow field at Barrow, Alaska, Polar Meteorol. Glaciol., 12, 1-9, 1998.

Aoki, T., Aoki, T., Fukabori, M., Hachikubo, A., Tachibana, Y., and Nishio, F.: Effects of snow physical parameters on spectral albedo and bi-directional reflectance of snow surface, J. Geophys. Res., 105, 10219-10236, 2000.

Aoki, T., Hachikubo, A., and Hori, M.: Effects of snow physical parameters on shortwave broadband albedos, J. Geophys. Res., 108, 4616, doi:10.1029/2003JD003506, 2003.

Aoki, T., Hori, M., Motoyoshi, H., Tanikawa, T., Hachikubo, A., Sugiura, K., Yasunari, T. J., Storvold, R., Eide, H. A., Stamnes, K., Li, W., Nieke, J., Nakajima, Y., and Takahashi, F.: ADEOSII/GLI snow/ice products: Part II - Validation results using GLI and MODIS data, Remote Sens. Environ., 111, 274-290, doi:10.1016/j.rse.2007.02.035, 2007.

Aoki, T., Kuchiki, K., Niwano, M., Kodama, Y., Hosaka, M., and Tanaka, T.: Physically based snow albedo model for calculating broadband albedos and the solar heating profile in snowpack for general circulation models, J. Geophys. Res., 116, D11114, doi:10.1029/2010JD015507, 2011.

Arnaud, L., Picard, G., Champollion, N., Dominé, F., Gallet, J.-C., Lefebvre, E., Fily, M., and Barnola, J.-M.: Measurement of vertical profiles of snow specific surface area with a $1 \mathrm{~cm}$ resolution using infrared reflectance: instrument description and validation, J. Glaciol., 57, 17-29, doi:10.3189/002214311795306664, 2011.

Berisford, D. F., Molotch, N. P., Durand, M. T., and Painter, T. H.: Portable spectral profiler probe for rapid snow grain size stratigraphy, Cold. Reg. Sci. Technol., 85, 183-190, 2013.

Bohren, C. F. and Huffman, D. R.: Absorption and scattering of light by small particles, Wiley, New York, 530 pp., 1983.

Boucher, O.: On aerosol direct shortwave forcing and the HenyeyGreenstein phase function, J. Atmos. Sci., 55, 128-134, 1998.

Carmagnola, C. M., Dominé, F., Dumont, M., Wright, P., Strellis, B., Bergin, M., Dibb, J., Picard, G., Libois, Q., Arnaud, L., and Morin, S.: Snow spectral albedo at Summit, Greenland: measurements and numerical simulations based on physical and chemical properties of the snowpack, The Cryosphere, 7, 1139-1160, doi:10.5194/tc-7-1139-2013, 2013.
Cauchy, A.: Note sur divers theoremes relatifs a la rectification des courbes et a la quadrature des surfaces, C. R. Acad. Sci. Paris, 13, 1060-1065, 1841.

Chýlek, P., Damiano, P., and Shettle, E. P.: Infrared emittance of water clouds, J. Atmos. Sci., 49, 1459-1472, 1992.

Coakley, K., and van Doorn, T.: Invariant moment shape description of microcalcifications in digital mammograms, Australas. Phys. Eng. Sci. Med., 18, 114-118, 1995.

Colbeck, S. C., Akitaya, E., Armstrong, R. L., Gubler, H., Lafeuille, J., Lied, K., McClung, D. M., and Morris, E. M.: The International Classification for Seasonal Snow on the Ground, International Commission on Snow and Ice and World Data Center A for Glaciology, University of Colorado, Boulder, CO, USA, 1990.

Dominé, F., Salvatori, R., Legagneux, L., Salzano, R., Fily, M., and Casacchia, R.: Correlation between the specific surface area and the short wave infrared (SWIR) reflectance of snow, Cold Reg. Sci. Technol., 46, 60-68, doi:10.1016/j.coldregions.2006.06.002, 2006.

Edwards, J. M. and Slingo, A.: Studies with a flexible new radiation code. I: Choosing a configuration for a large-scale model, Q. J. Roy. Meteorol. Soc., 122, 689-719, 1996.

Fassnacht, S. R., Williams, M. W., and Corrao, M. V.: Changes in the surface roughness of snow from millimetre to metre scales, Ecol. Complex., 6, 221-229, 2009.

Fierz, C., Armstrong, R. L., Durand, Y., Etchevers, P., Greene, E., McClung, D. M., Nishimura, K., Satyawali, P. K., and Sokratov, S. A.: The International Classification for Seasonal Snow on the Ground, IHP-VII Technical Documents in Hydrology No. 83, IACS Contribution No. 1, UNESCO-IHP, Paris, 2009.

Fily, M., Bourdelles, B., Dedieu, J. P., and Sergent, C.: Comparison of In situ and Landsat Thematic Mapper derived snow grain characteristics in the Alps, Remote Sens. Environ., 59, 452-460, 1997.

Flanner, M. G. and Zender, C. S.: Linking snowpack microphysics and albedo evolution, J. Geophys. Res. 111, D12208, doi:10.1029/2005JD006834, 2006.

Fujiyoshi, Y. and Wakahama, G.: On the snow particles comprising an aggregate, J. Atmos. Sci., 42, 1667-1674, 1985.

Gallet, J.-C., Dominé, F., Zender, C. S., and Picard, G.: Measurement of the specific surface area of snow using infrared reflectance in an integrating sphere at 1310 and $1550 \mathrm{~nm}$, The Cryosphere, 3, 167-182, doi:10.5194/tc-3-167-2009, 2009.

Gallet, J.-C., Dominé, F., Arnaud, L., Picard, G., and Savarino, J.: Vertical profile of the specific surface area and density of the snow at Dome C and on a transect to Dumont D'Urville, Antarctica - albedo calculations and comparison to remote sensing products, The Cryosphere, 5, 631-649, doi:10.5194/tc-5-6312011, 2011.

Gallet, J.-C., Dominé, F., Savarino, J., Dumont, M., and Brun, E.: The growth of sublimation crystals and surface hoar on the Antarctic plateau, The Cryosphere, 8, 1205-1215, doi:10.5194/tc-8-1205-2014, 2014.

Gay, M., Fily, M., Genthon, C., Frezzotti, M., Oerter, H., and Winther, J.-G.: Snow grain-size measurements in Antarctica, J. Glaciol., 48, 527-535, 2002.

Grenfell, T. C. and Warren S. G.: Representation of a nonspherical ice particle by a collection of independent spheres for scattering and absorption of radiation, J. Geophys. Res., 104, 3169731708, 1999. 
Grenfell, T. C., Perovich, D. K., and Ogren, J. A.: Spectral albedos of an alpine snowpack, Cold Reg. Sci. Technol., 4, 121-127, 1981.

Grenfell, T. C., Warren, S., and Mullen, P. C.: Reflection of solar radiation by the Antarctic snow surface at ultraviolet, visible, and near infrared wavelenghts, J. Geophys. Res., 99, 18669-18684, 1994.

Grenfell, T. C., Neshyba, S. P., and Warren, S. G.: Representation of a nonspherical ice particle by a collection of independent spheres for scattering and absorption of radiation: 3. Hollow columns and plates, J. Geophys. Res., 110, D17203, doi:10.1029/2005JD005811, 2005.

Hansen, J. E. and Travis, L. D.: Light scattering in planetary atmospheres, Space Sci. Rev., 16, 527-610, 1974.

Henyey, L. G. and Greenstein, J. L.: Diffuse radiation in the galaxy, Astrophys. J., 93, 70-83, 1941.

Hildebrand, T. and Rüegsegger, P.: A new method for the modelindependent assessment of thickness in three-dimensional images, J. Microsc., 185, 67-75, 1997.

Hudson, S. R. and Warren, S. G.: An explanation for the effect of clouds over snow on the top-of-atmosphere bidirectional reflectance, J. Geophys. Res., 112, D19202, doi:10.1029/2007JD008541, 2007.

Hudson, S. R., Warren, S. G., Brandt, R. E., Grenfell, T. C., and Six, D.: Spectral bidirectional reflectance of Antarctic snow: Measurements and parameterization, J. Geophys. Res., 111, D18106, doi:10.1029/2006JD007290, 2006.

Jin, Z., Charlock, T. P., Yang, P., Xie, Y., and Miller, W.: Snow optical properties for different particle shapes with application to snow grain size retrieval and MODIS/CERES radiance comparison over Antarctica, Remote Sens. Environ., 112, 3563-3581, 2008.

Kokhanovsky, A. A., Rozanov, V. V., Aoki, T., Odermatt, D., Brockmann, C., Krüger, O., Bouvet, M., Drusch, M., and Hori, M.: Sizing snow grains using backscattered solar light, Int. J. Remote Sens., 32, 6975-7008, doi:10.1080/01431161.2011.560621, 2011.

Kokhanovsky, A. A., and Zege, E. P.: Scattering optics of snow, Appl. Optics, 43, 1589-1602, 2004.

Kuchiki, K., Aoki, T., Tanikawa, T., and Kodama, Y.: Retrieval of snow physical parameters using a ground-based spectral radiometer, Appl. Optics, 48, 5567-5582, 2009.

Kuester, M., Thome, K., Krause, K., Canham, K., and Whittington, E.: Comparison of surface reflectance measurements from three ASD FieldSpec FR spectroradiometers and one ASD FieldSpec VNIR spectroradiometer, in: IEEE 2001 International Geoscience and Remote Sensing Symposium, IGARSS '01, Sydney, 72-74, 2001.

Kuhn, M.: Anisotropic reflection from sastrugi fields, Antarct. J. U. S., 9, 123-125, 1974.

Leroux, C. and Fily, M.: Modelling the effect of sastrugi on snow reflectance, J. Geophys. Res., 103, 25779-88, 1998.

Libois, Q., Picard, G., France, J. L., Arnaud, L., Dumont, M., Carmagnola, C. M., and King, M. D.: Influence of grain shape on light penetration in snow, The Cryosphere, 7, 1803-1818, doi:10.5194/tc-7-1803-2013, 2013.

Lindqvist, H., Muinonen, K., Nousiainen, T., Um, J., McFarquhar, G. M., Haapanala, P., Makkonen, R., and Hakkarainen, H.: Ice- cloud particle habit classification using principal components, J. Geophys. Res., 117, D16206, doi:10.1029/2012JD017573, 2012.

Liou, K. N., Gu, Y., Yue, Q., and McFarguhar, G.: On the correlation between ice water content and ice crystal size and its application to radiative transfer and general circulation models, Geophys. Res. Lett., 35, L13805, doi:10.1029/2008GL033918, 2008.

Liou, K. N., Takano, Y., and Yang, P.: Light absorption and scattering by aggregates: Application to black carbon and snow grain, J. Quant. Spectrosc. Ra., 112, 1581-1594, doi:10.1016/j.jqsrt.2011.03.007, 2011

Lubin, D. and Vogelmann, A. M.: The influence of mixed-phase clouds on surface shortwave irradiance during the Arctic spring, J. Geophys. Res., 116, D00T05, doi:10.1029/2011JD015761, 2011.

Lyapustin, A., Tedesco, M., Wang, Y., Aoki, T., Hori, M., and Kokhanovsky, A.: Retrieval of snow grain size over Greenland from MODIS, Remote Sens. Environ., 113, 1976-1987, 2009.

Lyapustin, A., Gatebe, C. K., Kahn, R., Brandt, R., Redemann, J., Russell, P., King, M. D., Pedersen, C. A., Gerland, S., Poudyal, R., Marshak, A., Wang, Y., Schaaf, C., Hall, D., and Kokhanovsky, A.: Analysis of snow bidirectional reflectance from ARCTAS spring-2008 campaign, Atmos. Chem. Phys., 10, 4359-4375, doi:10.5194/acp-10-4359-2010, 2010.

Mac Arthur, A., MacLellan, C. J., and Malthus, T.: The Fields of View and Directional Response Functions of Two Field Spectroradiometers, IEEE T. Geosci. Remote, 50, 3892-3907, 2011.

Manninen, T.: Surface roughness of Baltic Sea ice, J. Geophys. Res., 102, 1119-1139, 1997.

Mätzler, C.: Autocorrelation functions of granular media with free arrangement of spheres, spherical shells or ellipsoids, J. Appl. Phys., 81, 1509-1517, 1997.

Mishchenko, M. M., Dlugach, J. M., Yanovitskij, E. G., and Zakharova, N. T.: Bidirectional reflectance of flat, optically thick particulate layers: an efficient radiative transfer solution and applications to snow and soil surfaces, J. Quant. Spectrosc. Ra., 63, 409-432, 1999.

Nakamura, T., Abe, O., Hasegawa, T., Tamura, R., and Ohta, T.: Spectral reflectance of snow with a known grain-size distribution in successive metamorphism, Cold Reg. Sci. Technol., 32, 1326, 2001

Neshyba, S. P., Grenfell, T. C., and Warren, S. G.: Representation of a nonspherical ice particle by a collection of independent spheres for scattering and absorption of radiation: 2. Hexagonal columns and plates, J. Geophys. Res., 108, 4448, doi:10.1029/2002JD003302, 2003.

Nolin, A. W. and Dozier, J.: A hyperspectral method for remotely sensing the grain size of snow. Remote Sens. Environ., 74, $207-$ 216, doi:10.1016/S0034-4257(00)00111-5, 2000.

Painter, T. H. and Dozier, J.: Measurements of the hemisphericaldirectional reflectance of snow at fine spectral and angular resolution, J. Geophys. Res., 109, D18115, doi:10.1029/2003JD004458, 2004.

Painter, T. H., Dozier, J., Roberts, D. A., Davis, R. E., and Green, R. O.: Retrieval of subpixel snow-covered area and grain size from imaging spectrometer data, Remote Sens. Environ., 85, 64-77, 2003.

Painter, T. H., Molotch, N. P., Cassidy, M., Flanner, M., and Steffen, K.: Contact Spectroscopy for Determination of Stratigraphy of Optical Grain Size, J. Glaciol., 53, 121-127, 2007. 
Picard, G., Arnaud, L., Dominé, F., and Fily, M.: Determining snow specific surface area from near-infrared reflectance measurements: numerical study of the influence of grain shape, Cold Reg. Sci. Technol., 56, 10-17, 2009.

Pirazzini, R.: Surface albedo measurements over Antarctic sites in summer, J. Geophys. Res., 109, D20118, doi:10.1029/2004JD004617, 2004.

Pringle, D. J., Miner, J. E., Eicken, H., and Golden, K. M.: Pore space percolation in sea ice single crystals, J. Geophys. Res., 114, C12017, doi:10.1029/2008JC005145, 2009.

Räisänen, P., Kokhanovsky, A., Guyot, G., Jourdan, O., and Nousiainen, T.: Parameterization of single-scattering properties of snow, The Cryosphere, 9, 1277-1301, doi:10.5194/tc-9-12772015, 2015.

Rizk, A., Paul, G., Incardona, P., Bugarski, M., Niemann, A., Ziegler, U., Berger, P., and Sbalzarini, I. F.: Segmentation and quantification of subcellular structures in fluorescence microscopy images using Squassh, Nat. Protocols, 9, 586-596, 2014.

Schneebeli, M. and Sokratov, S. A.: Tomography of temperature gradient metamorphism of snow and associated changes in heat conductivity, Hydrol. Process., 18, 3655-3665, doi:10.1002/hyp.5800, 2004

Sjöblom, A. and Smedman, A.: The turbulent kinetic energy budget in the marine atmospheric boundary layer, J. Geophys. Res., 107, 3142, doi:10.1029/2001JC001016, 2002.

Stamnes, K., Tsay, S. C., Wiscombe, W., and Jayaweera, K: Numerically stable algorithm for discrete-ordinate-method radiative transfer in multiple scattering and emitting layered media, Appl. Optics, 27, 2502-2509, 1988.

Stamnes, K., Li, W., Eide, H., Aoki, T., Hori, M., and Storvold, R.: ADEOS-II/GLI snow/ice products - Part I: Scientific Basis, Remote Sens. Environ., 111, 258-273, 2007.

Tedesco, M. and Kokhanovsky, A. A.: The semi-analytical snow retrieval algorithm and its application to MODIS data, Remote Sens. Environ., 111, 228-241, 2007.
Vihma, T., Mattila, O.-P., Pirazzini, R., and Johansson, M. M.: Spatial and temporal variability in summer snow pack in Dronning Maud Land, Antarctica, The Cryosphere, 5, 187-201, doi:10.5194/tc-5-187-2011, 2011.

Warren, S. G.: Optical properties of snow, Rev. Geophys., 20, 6789, 1982.

Warren, S. G. and Brandt, R. E.: Optical constants of ice from the ultraviolet to the microwave: A revised compilation, J. Geophys. Res., 113, D14220, doi:10.1029/2007JD009744, 2008.

Warren, S. G. and Clarke, A. D.: Soot in the atmosphere and snow surface of Antarctica, J. Geophys. Res., 95, 1811-1816, 1990.

Warren, S. G., Brandt, R. E., and O'Rawe Hinton, P.: Effect of surface roughness on bidirectional reflectance of Antarctic snow, J. Geophys. Res., 103, 25789-25807, 1998.

Wiscombe, W. J.: The delta-M method: rapid yet accurate radiative flux calculations for strongly asymmetric phase functions, J. Atmos. Sci., 34, 1408-1422, 1977.

Wiscombe, W. J. and Warren, S. G.: A model for the spectral albedo of snow, I, Pure snow, J. Atmos. Sci., 37, 2712-2733, 1980.

Yang, P., Baum, B. A., Heymsfield, A. J., Hu, Y. X., Huang, H.L., Tsay, S.-C., and Ackerman, S.: Single-scattering properties of droxtals, J. Quant. Spectrosc. Ra., 79-80, 1159-1169, 2003.

Yang, P., Bi, L., Baum, B. A., Liou, K.-N., Kattawar, G. W., Mishchenko, M. I., and Cole, B.: Spectrally consistent scattering, absorption, and polarization properties of atmospheric ice crystals at wavelengths from 0.2 to $100 \mu \mathrm{m}$, J. Atmos. Sci., 70, 330-347, doi:10.1175/JAS-D-12-039.1, 2013.

Zhou, X., Li, S., and Stamnes, K.: Effects of vertical inhomogeneity on snow spectral albedo and its implication for optical remote sensing of snow, J. Geophys. Res., 108, 4738, doi:10.1029/2003JD003859, 2003.

Zhuravleva, T. and Kokhanovsky, A.: Influence of surface roughness on the reflective properties of snow, J. Quant. Spectrosc. Ra., 112, 1353-1368, doi:10.1016/j.jqsrt.2011.01.004, 2011. 